\title{
Ring-closing metathesis mediated total synthesis of microcarpalide and herbarumin III
}

\author{
Mukund K. Gurjar*, Ravi Nagaprasad, C. V. Ramana, Sukhen Karmakar, and Debendra \\ K. Mohapatra \\ National Chemical Laboratory \\ Pune-411008, India \\ E-mail:gurjar@dalton.ncl.res.in
}

\section{Dedicated to Dr. A. V. Rama Rao on the occasion of his $70^{\text {th }}$ birthday}

(received 20 Jan 05; accepted 18 Feb 05; published on the web 24 Feb 05)

\begin{abstract}
Total synthesis of naturally occurring microcarpalide and herbarumin III are described. The ringclosing metathesis (RCM) approach to coin the medium sized rings present in their molecular structures form the basic premise of this investigation.
\end{abstract}

Keywords: Microcarpalide, herbarumin III, ring-closing metathesis (RCM), microfilament, phosphodiesterase

\section{Introduction}

Medium ring compounds having a ring size between 8 to $11^{1}$ are increasingly being isolated from natural resources. By the virtue of their biological significance, the synthesis of these natural products has attracted attention of many groups. This article describes the RCM based approaches to the total synthesis of two medium ring sized natural products microcarpalide (1) and herbarumin III (4). Bio-assay guided purification of fermentation broth of Ficus microcarpa L led to the isolation of microcarpalide ${ }^{2 a}(\mathbf{1})$, structurally related to a family of phytotoxins ${ }^{3}$ but differs in the hydroxylation pattern, the double bond position within the 10-membered lactone and the length of the side chain at $\mathrm{C}$-10. Microcarpalide ${ }^{4}$ possesses microfilament disrupting activity. On similar lines, fermentation broth and mycelium of the fungus Phoma herbarum produced three new phytotoxic nonenolides named as herbarumin (I-III) (2-4). Herbarumin I-III interacts with bovine-brain calmodulin and inhibits the activation of the calmodulin-dependent enzyme camp phosphodiesterase. 


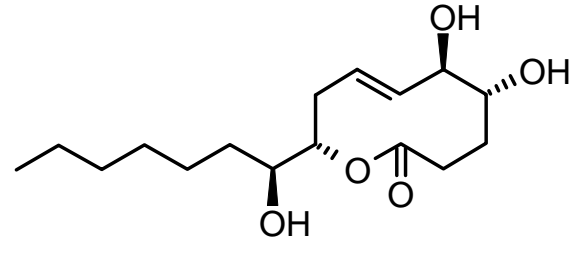

1 (Microcarpalide)<smiles>[R2][C@H]1CC/C=C/[C@@H](O)[C@H]([R4])[C@@H]1CCC</smiles>

$$
\begin{aligned}
& 2 \mathrm{R}^{1}=\mathrm{OH}, \mathrm{R}^{2}=\mathrm{H} \text { (Herbarumin I) } \\
& 3 \mathrm{R}^{1}=\mathrm{H}, \mathrm{R}^{2}=\mathrm{OH}(\text { Herbarumin II) } \\
& 4 \mathrm{R}^{1}=\mathrm{R}^{2}=\mathrm{H} \text { (Herbarumin III) }
\end{aligned}
$$

Figure 1. Structures of microcarpalide and herbarumins.

With $\mathrm{RCM}^{5}$ reaction destined to provide the oxecin ring framework, it was apparent that micrcarpalide (1) was disassembled into fragments 5 and $\mathbf{6}$ having terminal olefins group whilst the hydroxyl and acid groups at the other ends of $\mathbf{5}$ and $\mathbf{6}$ ensured their union through esterification. ${ }^{6}$ Both the fragments $(\mathbf{5} \& \mathbf{6})$ containing two chiral centers were realized by facile zinc mediated elimination ${ }^{7}$ and Sharpless asymmetric dihydroxylation ${ }^{8}$ as delineated in Scheme 1.

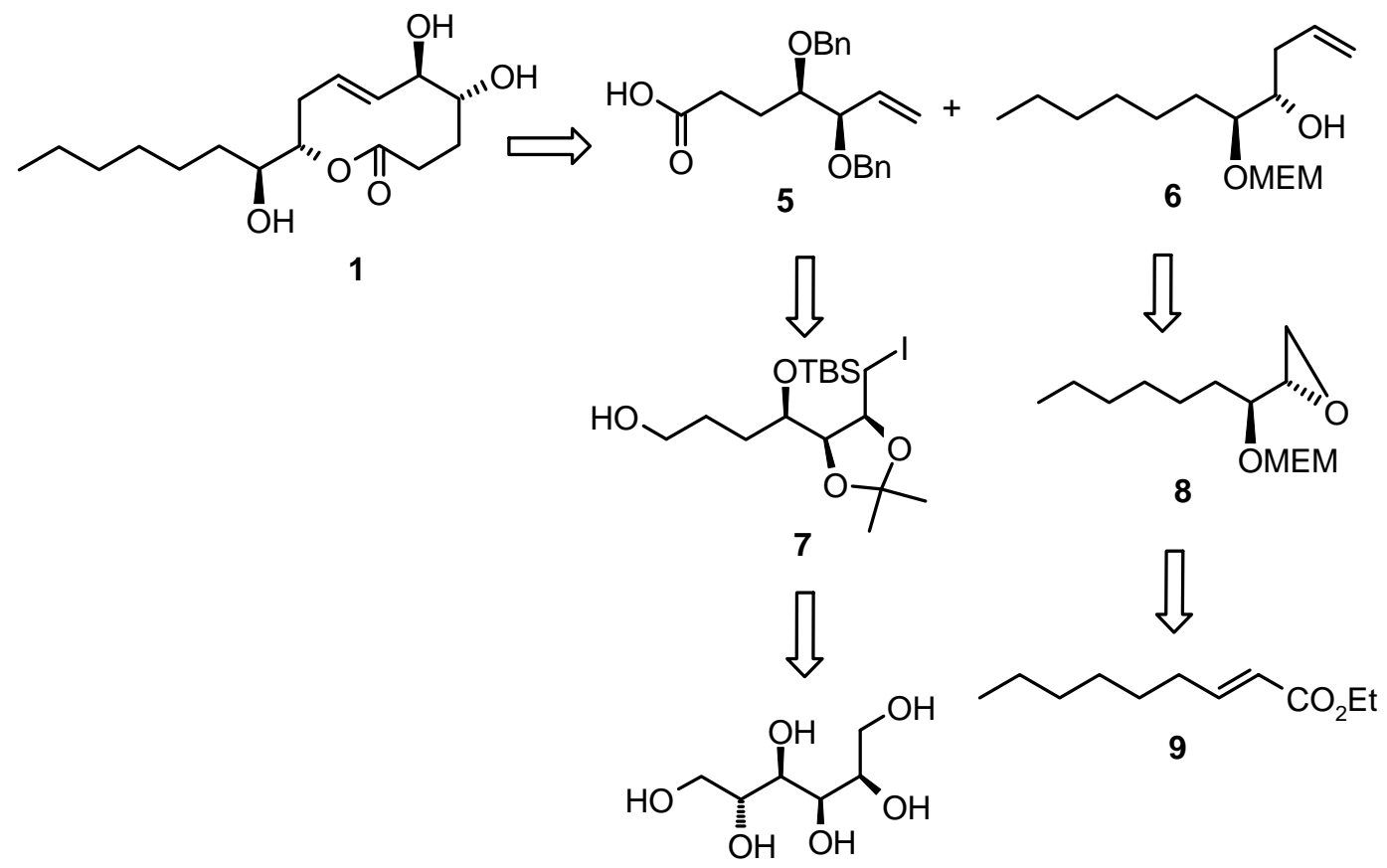

\section{D-Mannose}

\section{Scheme 1}


On a similar premise, the synthetic strategy for herbarumin III (4) $)^{9,10}$ relied on the union of two fragments 11 and 12. The synthesis of $\mathbf{1 1}$ was planned from D-glucose whose steregenic centers at C-2 and C-4 were correlated with C-8 and C-10 of herbarumin III (4).<smiles>CCC[C@H](C[C@@H](O)/C=C/CCCCC(=O)O)OC</smiles><smiles>C=CCCCC(=O)O[C@@H](CCC)C[C@H](O)C=C</smiles><smiles>C=C=CCC[C@@H](O)C[C@@H](C=C)OC(C)(C)C</smiles><smiles>C=CCCCC(=O)O</smiles><smiles>O=C[C@H](O)[C@@H](O)[C@H](O)[C@H](O)CO</smiles>

\section{Scheme 2}

\section{Results and Discussions}

\section{Total synthesis of microcarpalide (1)}

D-mannose was converted into the conjugated ester derivative (13) by a reported sequence. ${ }^{11,12}$ Subsequent treatment of 13 with DIBAL-H in $\mathrm{CH}_{2} \mathrm{Cl}_{2}$ at $-78{ }^{\circ} \mathrm{C}$ for $1 \mathrm{~h}$ afforded the allyl alcohol whose primary hydroxyl was protected as the MEM-ether (14). ${ }^{13}$ The structural identity was secured by the interpretation of the ${ }^{1} \mathrm{H}$ NMR spectrum. For example, two singlets resonated at $\delta$ 4.67 and $\delta 3.4$ were attributed to methylene and methoxyl groups of MEM. 14 was hydrogenolysed in the presence of $\mathrm{Pd} / \mathrm{C}$ and consequently exposed to $\mathrm{LAH}$ in THF to produce the diol derivative (16). 

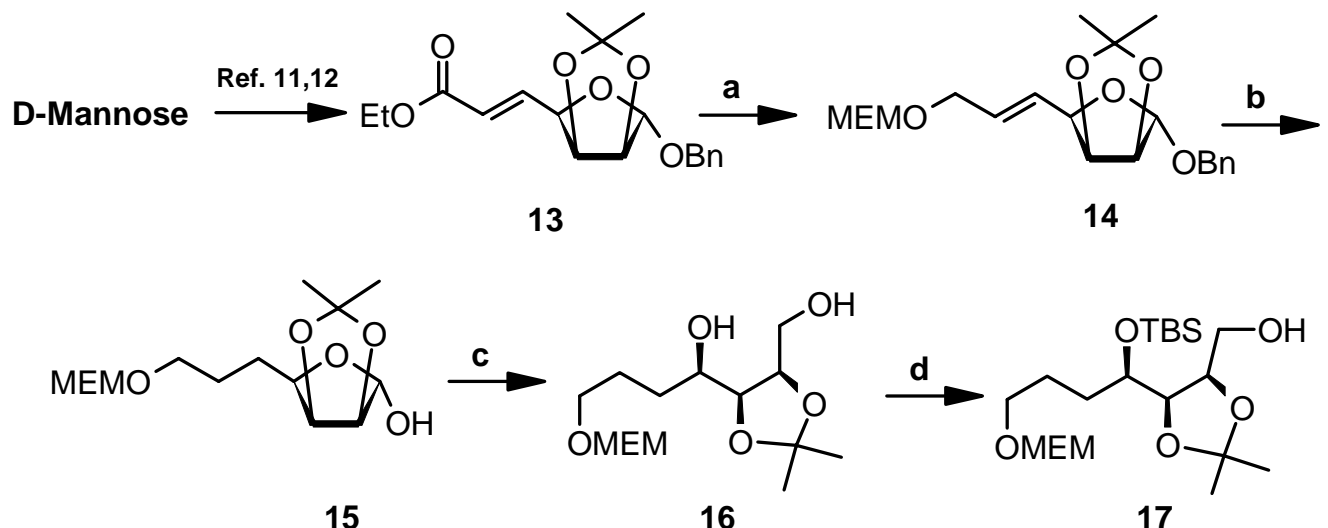

Scheme 3. Reagents and conditions: (a) (i) DIBAL-H, $\mathrm{CH}_{2} \mathrm{Cl}_{2},-78{ }^{\circ} \mathrm{C}$ to $0{ }^{\circ} \mathrm{C}, 2 \mathrm{~h}, 92 \%$; (ii) MEM-Cl, ${ }^{i} \mathrm{Pr}_{2} \mathrm{NEt}, \mathrm{CH}_{2} \mathrm{Cl}_{2}$, rt, 10 h, 78\%; (b) $\mathrm{H}_{2}, 10 \%$ Pd-C, $\mathrm{MeOH}, 6$ bar, $60{ }^{\circ} \mathrm{C}, 4$ h, 96\%; (c) $\mathrm{LiAlH}_{4}$, THF, rt, $1 \mathrm{~h}, 92 \%$; (d) (i) $\left(\mathrm{CH}_{3}\right)_{3} \mathrm{CCOCl}$, pyridine, $0{ }^{\circ} \mathrm{C}$-rt, $1 \mathrm{~h}, 91 \%$; (ii) TBSCl, DMF, imidazole, rt, 4 h, $90 \%$; (iii) DIBAL-H, $\mathrm{CH}_{2} \mathrm{Cl}_{2},-78{ }^{\circ} \mathrm{C}, 1 \mathrm{~h}, 89 \%$.

In order to introduce iodide at $\mathrm{C}-1$, the protection-deprotection ${ }^{14-16}$ sequence on $\mathbf{1 6}$ was performed to obtain the primary hydroxyl derivative (17). Treatment of 17 with $\mathrm{I}_{2}$, TPP and imidazole in toluene at room temperature led to the formation of 7 in $40 \%$ yield. Addition of $\mathrm{Et}_{3} \mathrm{~N}$ marginally improved the yield of 7 (45\%), however, the formation of the cyclized product $18(15 \%)$ was also noticed (Scheme 4). ${ }^{17 \mathrm{a}}$ The iodination reaction carried out in the presence of $\mathrm{I}_{2}$, TPP and imidazole but in benzene-ether $(2: 1)$ medium $^{17 b}$ provided 7 in $86 \%$ yield. In the ${ }^{1} \mathrm{H}$ NMR spectrum of 7, the resonances due to $\mathrm{CH}_{2} \mathrm{I}$ were located at 3.12 as a triplet $(J=10.4 \mathrm{~Hz})$, and at 3.27 as a doublet of doublet $(J=10.4,3.3 \mathrm{~Hz})$ (Scheme 5).

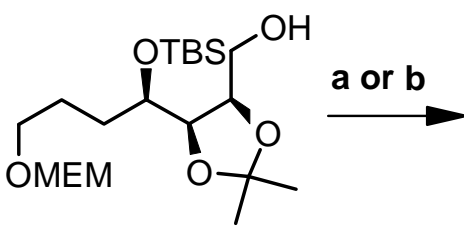

17

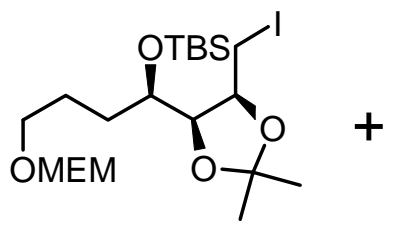

7

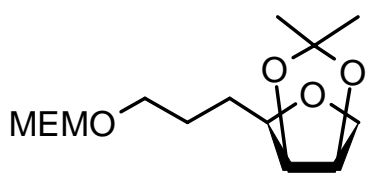

18

Scheme 4. Reagents and conditions: (a) $\mathrm{I}_{2}, \mathrm{PPh}_{3}$, imidazole, toluene, rt, 4 h, 40\%; (b) $\mathrm{I}_{2}, \mathrm{PPh}_{3}$, imidazole, $\mathrm{Et}_{3} \mathrm{~N}, \mathrm{CH}_{2} \mathrm{Cl}_{2}$, rt, $2.5 \mathrm{~h}, 45 \%$ (7) and $15 \%$ (18). 


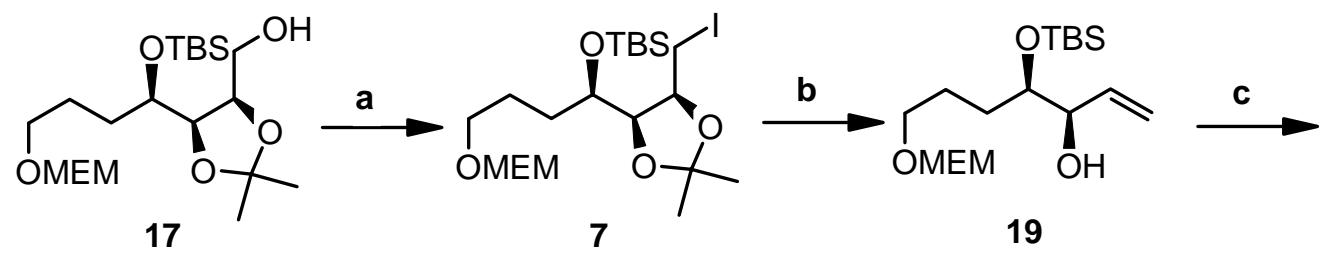

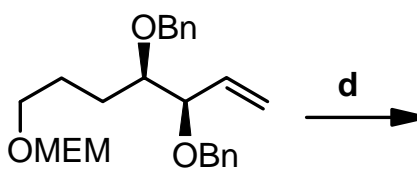

20<smiles>C=C[C@@H](OCc1ccccc1)[C@@H](Br)CCCO</smiles>

21

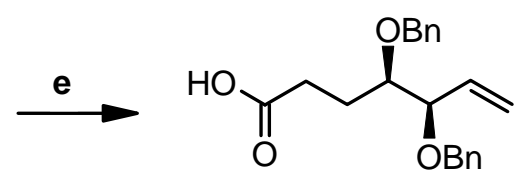

5

Scheme 5. Reagents and conditions: (a) $\mathrm{I}_{2}, \mathrm{PPh}_{3}$, imidazole, ether-benzene (2:1), rt, $1.5 \mathrm{~h}, 86 \%$. (b) $\mathrm{Zn}$, ethanol, reflux, $1.5 \mathrm{~h}, 96 \%$. (c) (i) $n-\mathrm{Bu}_{4} \mathrm{NF}$, THF, $0{ }^{\circ} \mathrm{C}$ to rt, $4 \mathrm{~h}, 85 \%$. (ii) $\mathrm{NaH}, \mathrm{BnBr}$, DMF, $0{ }^{\circ} \mathrm{C}$ - rt, 2.5 h, 86\%. (d) PPTS, $t$-BuOH, $80{ }^{\circ} \mathrm{C}, 1.5$ h, 85\%. (e) (i) $(\mathrm{COCl})_{2}$, DMSO, Et ${ }_{3} \mathrm{~N}$, $\mathrm{CH}_{2} \mathrm{Cl}_{2},-78{ }^{\circ} \mathrm{C}, 1 \mathrm{~h}, 90 \%$. (ii) $\mathrm{NaClO}_{2}, \mathrm{DMSO}, \mathrm{NaH}_{2} \mathrm{PO}_{4}, \mathrm{rt}, 1.5 \mathrm{~h}, 92 \%$.

Conversion of 7 into 19 was accomplished by Zinc mediated elimination ${ }^{7}$ reaction in refluxing ethanol. In the ${ }^{1} \mathrm{H}$ NMR spectrum of 19, typical pattern for terminal olefinic protons were observed. The dibenzyl derivative $\mathbf{2 0}$ was produced by desilylation ${ }^{12}$ followed by benzylation and deprotection of MEM group. ${ }^{18}$ Compound $\mathbf{2 1}$ was transformed into the acid derivative in two steps which first involved Swern oxidation and reaction with aqueous $\mathrm{NaClO}_{2}$ in DMSO and phosphate buffer. ${ }^{19}{ }^{1} \mathrm{H}$ NMR and ${ }^{13} \mathrm{C}$ spectra of 5 were compatible with the assigned structure (Scheme 5).

The journey toward the synthesis of $\mathbf{6}$ began with commercially available 1-heptanal (22), which upon two-carbon Wittig homologation with $\mathrm{Ph}_{3} \mathrm{P}=\mathrm{CHCO}_{2} \mathrm{Et}$ in benzene at $80{ }^{\circ} \mathrm{C}$ gave 9 as a mixture of trans and cis isomers in the ratio of $85: 15 .^{20}$ They were separated by silica gel chromatography and the major trans isomer was subjected to Sharpless asymmetric dihydroxylation procedure ${ }^{8}$ in the presence of (DHQ) ${ }_{2} \mathrm{PHAL}, \mathrm{K}_{2} \mathrm{Fe}(\mathrm{CN})_{6}, \mathrm{~K}_{2} \mathrm{CO}_{3}, \mathrm{MeSONH}_{2}$ and $\mathrm{K}_{2} \mathrm{OsO}_{4} ; 2 \mathrm{H}_{2} \mathrm{O}$ in $t-\mathrm{BuOH}-\mathrm{H}_{2} \mathrm{O}(1: 1)$ at $0{ }^{\circ} \mathrm{C}$ for $10 \mathrm{~h}$ to afford the diol 23. The compound was thoroughly investigated by the ${ }^{1} \mathrm{H}$ and ${ }^{13} \mathrm{C}$ NMR spectra and elemental analysis (Scheme 6). Enatiomeric purity of 23 was estimated to be $97.5 \%$ ee, by chiral HPLC analysis of the corresponding dibenzoate using a chiracel OD column (1\% $i$-propanol/n-hexane, flow rate 2.0 $\mathrm{mL} / \mathrm{min}, \lambda=225 \mathrm{~nm}$ ). The diol 23 was treated with 2,2-dimethoxypropane-cat. $p$-TSA, reduction with DIBAL-H in $\mathrm{CH}_{2} \mathrm{Cl}_{2}$ at $-78{ }^{\circ} \mathrm{C}$ followed by tosylation gave $24 .{ }^{21}$ Acid hydrolysis, ${ }^{22}$ cyclisation with $\mathrm{K}_{2} \mathrm{CO}_{3}$ in $\mathrm{MeOH}$ followed by protection of hydroxyl group as the MEM group to afford 8. The ${ }^{1} \mathrm{H} \mathrm{NMR},{ }^{13} \mathrm{C}$ NMR spectra and elemental analysis were in accordance with the structure of $\mathbf{8}$. The ring opening reaction of the oxirane $\mathbf{8}$ with vinyl magnesium bromide in THF at $0{ }^{\circ} \mathrm{C}$ led to a mixture of products in which the require product $\mathbf{6}$ was formed as a minor product. This was partly attributed to side reactions particularly iodide mediated ring opening reaction (Scheme 6). However, the two step sequence involving opening of epoxide ring with lithium acetylide-EDA complex ${ }^{23}$ in DMSO followed by partial reduction of the triple bond in 
the presence of Lindlar's catalyst ${ }^{24}$ afforded compound 6 (Scheme 7). The ${ }^{1} \mathrm{H}$ NMR spectrum of 6 showed resonances for terminal olefinic protons at $\delta$ 5.06-5.17 (multiplet), and at $\delta 5.88$ (dt, $J$ $=17.6,10.6,7.0 \mathrm{~Hz})$. The ${ }^{13} \mathrm{C}$ NMR spectrum indicated peaks at 117.1, 134.9 for olefinic carbons.<smiles>CCCCCCC(=O)OCCCCCCCCCC=CC(=O)OCCCCCCCCC[C@@H](O)[C@H](O)CC</smiles>

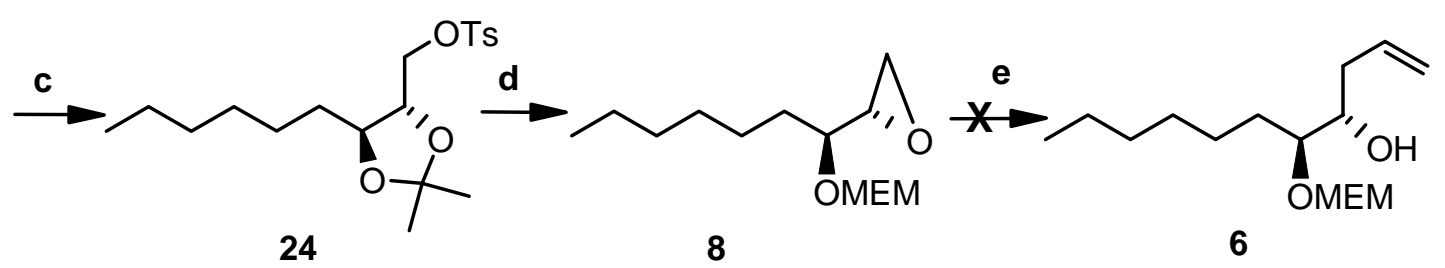

Scheme 6. Reagents and conditions: (a) $\mathrm{Ph}_{3} \mathrm{P}=\mathrm{CHCO}_{2} \mathrm{Et}$, benzene, $80{ }^{\circ} \mathrm{C}, 4 \mathrm{~h}$, trans:cis (85:15), $89 \%$. (b) AD-mix- $\alpha, t-\mathrm{BuOH}, \mathrm{H}_{2} \mathrm{O}, 0{ }^{\circ} \mathrm{C}, 10 \mathrm{~h}, 94 \%$. (c) (i) 2,2-dimethoxypropane, $p$-TsOH, $\mathrm{CH}_{2} \mathrm{Cl}_{2}$, rt, $4 \mathrm{~h}, 96 \%$. (ii) DIBAL-H, $\mathrm{CH}_{2} \mathrm{Cl}_{2},-78{ }^{\circ} \mathrm{C}, 1 \mathrm{~h}, 97 \%$. (iii) $p$ - $\mathrm{TsCl}$, pyridine, $0{ }^{\circ} \mathrm{C}-\mathrm{rt}, 7 \mathrm{~h}$, 96\%. (d) (i) conc. $\mathrm{HCl}$ (cat.), $\mathrm{MeOH}$, rt, 3 h, 87\%. (ii) $\mathrm{K}_{2} \mathrm{CO}_{3}, \mathrm{MeOH}, \mathrm{rt}, 1.5 \mathrm{~h}, 85 \%$. (iii) MEM$\mathrm{Cl},{ }^{i} \mathrm{Pr}_{2} \mathrm{NEt}, \mathrm{CH}_{2} \mathrm{Cl}_{2}, \mathrm{rt}, 4 \mathrm{~h}, 91 \%$. (e) vinylmagnesium bromide, $\mathrm{CuCN}, \mathrm{THF},-40{ }^{\circ} \mathrm{C}-0{ }^{\circ} \mathrm{C}, 12 \mathrm{~h}$.

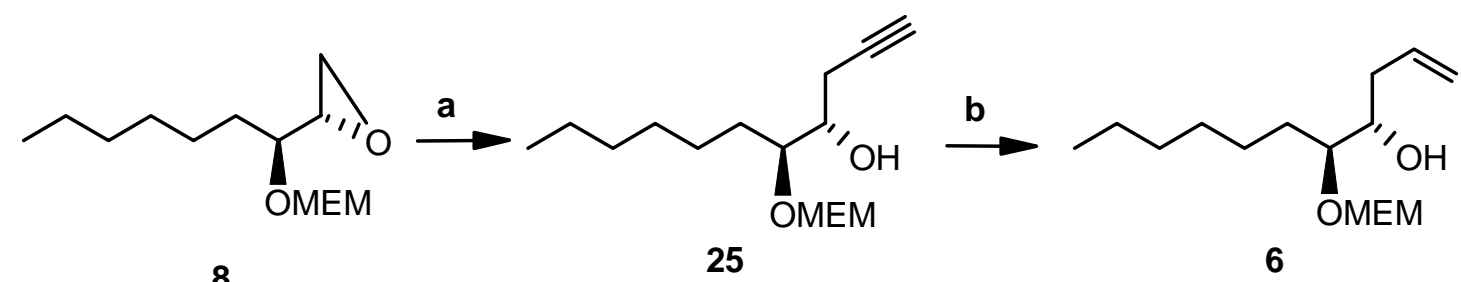

Scheme 7. Reagents and conditions: (a) $\mathrm{LiC} \equiv \mathrm{CH}$ :ethylenediamine, DMSO, rt, $12 \mathrm{~h}, 86 \%$. (b) $\mathrm{H}_{2}, \mathrm{Pd} / \mathrm{BaSO}_{4}$, quinoline, benzene, 1 bar, $0.5 \mathrm{~h}, 91 \%$.

The coupling reaction of fragments $\mathbf{5}$ and $\mathbf{6}$ was performed in the presence of $\mathrm{DCC}^{6}$ and DMAP in $\mathrm{CH}_{2} \mathrm{Cl}_{2}$. The structure of the derived ester 26 was confirmed by the ${ }^{1} \mathrm{H}$ and ${ }^{13} \mathrm{C}$ NMR spectra (Scheme 8). In the ${ }^{1} \mathrm{H}$ NMR spectrum, a clear-cut down field shift of H-10 signal was observed, which indicated that the ester formation had indeed occurred. 


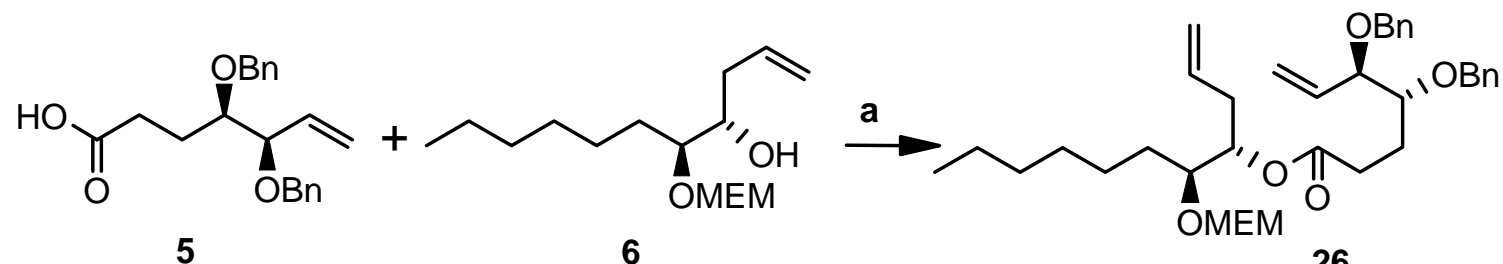

5 6

26

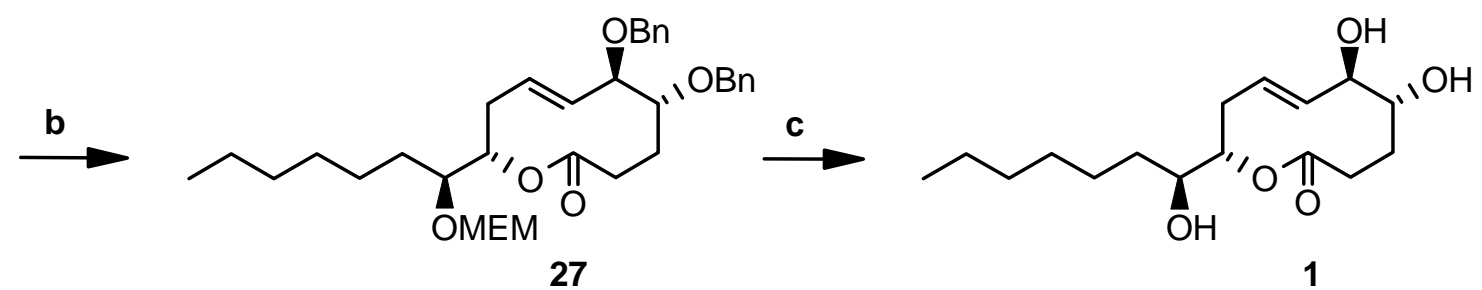

Scheme 8. Reagents and conditions: (a) DCC, DMAP, $\mathrm{CH}_{2} \mathrm{Cl}_{2}$, rt, $18 \mathrm{~h}, 76 \%$. (b) ( $\left.\mathrm{PCy}_{3}\right)_{2}$ $\mathrm{Ru}(\mathrm{Cl})_{2}=\mathrm{CHPh}\left(20 \mathrm{~mol} \%\right.$ ), $\mathrm{CH}_{2} \mathrm{Cl}_{2}$, reflux, $28 \mathrm{~h}, 67 \%$. (c) $\mathrm{TiCl}_{4}, \mathrm{CH}_{2} \mathrm{Cl}_{2}, 0{ }^{\circ} \mathrm{C}, 0.5 \mathrm{~h}, 76 \%$.

Ring closing metathesis reaction ${ }^{5}$ of 26 with Grubbs' catalyst $\left(\mathrm{Cl}_{2} \mathrm{PCy}{ }_{3} \mathrm{Ru}=\mathrm{CHPh}\right)$ in degassed $\mathrm{CH}_{2} \mathrm{Cl}_{2}$ afforded the ten-membered lactone derivative as a mixture of two geometrical isomers in 10:1 ratio whose silica gel purification gave the pure $E$-isomer (27). The ${ }^{1} \mathrm{H}$ NMR spectrum of 27 showed two olefinic protons at $\delta 5.64$ and $5.73(J=15.8)$ (Scheme 8). For the deprtection of MEM-group, 27 was exposed to titanium tetrachloride ${ }^{10,21}$ in $\mathrm{CH}_{2} \mathrm{Cl}_{2}$ at $0{ }^{\circ} \mathrm{C}$. However, this treatment resulted in the simultaneous removal of MEM as well benzyl ethers and led to the formation of microcarpalide (1) whose NMR spectrum in $\mathrm{CD}_{3} \mathrm{CN}$ revealed two slowly inter-converting conformers in a ration of 76:24. The resonances due to $\mathrm{H}-10$ were seen at 4.81 $\mathrm{ppm}$ for the major conformer and at $4.63 \mathrm{ppm}$ for the minor. This conformer ratio is identical to the 3.5:1 value reported for natural product in the in the same solvent.

\section{Total synthesis of herbarumin III (4)}

The synthesis of herbarumin III began with the preparation of fragment 11 from D-glucose. The 3-deoxy-derivative ${ }^{25 a-b}$ of diacetonide-D-glucose selectively deprotected and then cleaved ${ }^{26}$ to give the aldehyde 30 which was treated with $\mathrm{EtPPh}_{3} \mathrm{Br}$ and $n$-BuLi at $-78{ }^{\circ} \mathrm{C}$ and then hydrogenated by using $10 \% \mathrm{Pd} / \mathrm{C}$ to afford the $n$-propyl sugar derivative 31 (Scheme 9 ). 


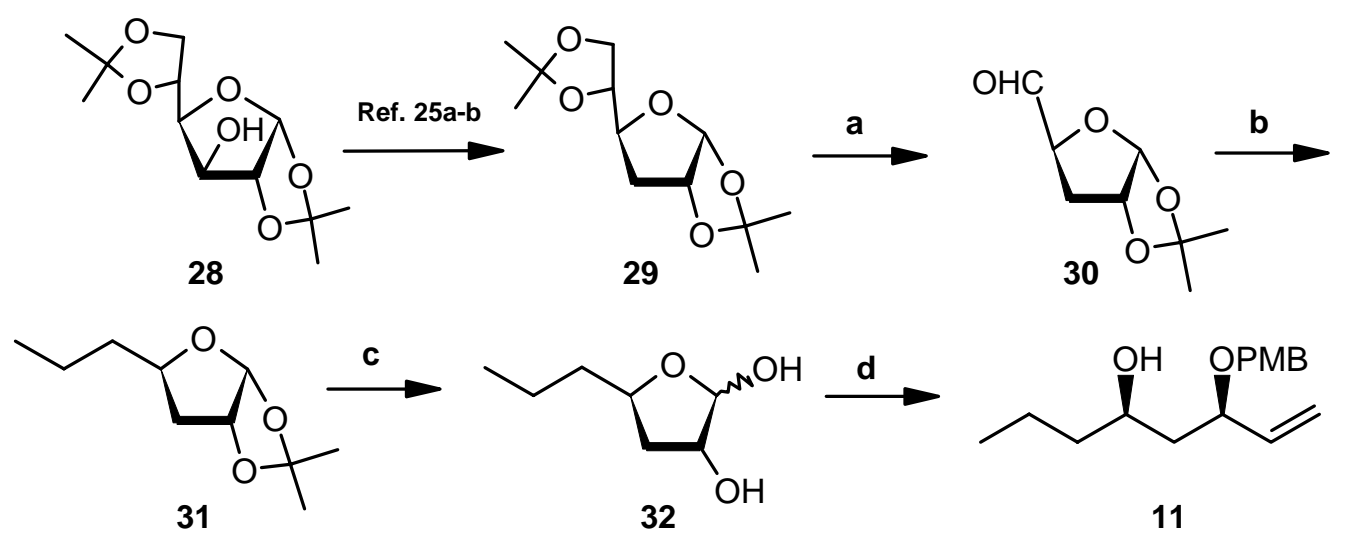

Scheme 9. Reagents and conditions: (a) (i) $0.8 \% \mathrm{H}_{2} \mathrm{SO}_{4}, \mathrm{MeOH}, \mathrm{rt}, 12 \mathrm{~h}, 84 \%$. (ii) Silica gel supported $\mathrm{NaIO}_{4}, \mathrm{CH}_{2} \mathrm{Cl}_{2}$, rt, $30 \mathrm{~min}, 95 \%$. (b) (i) $\mathrm{Br}^{-} \mathrm{P}^{+} \mathrm{Ph}_{3} \mathrm{CH}_{2} \mathrm{CH}_{3}, n-\mathrm{BuLi}, \mathrm{THF},-78{ }^{\circ} \mathrm{C}-0{ }^{\circ} \mathrm{C}$, $3 \mathrm{~h}, 82 \%$. (ii) $\mathrm{H}_{2}, \mathrm{Pd} / \mathrm{C}, 1$ bar, rt, $3 \mathrm{~h}, 92 \%$. (c) $20 \% \mathrm{AcOH}$ in $\mathrm{H}_{2} \mathrm{O}$, conc. $\mathrm{H}_{2} \mathrm{SO}_{4}$ (catalytic), reflux, 6 h, 93\%. (d) (i) $\mathrm{I}^{-} \mathrm{P}^{+} \mathrm{Ph}_{3} \mathrm{CH}_{3}, n$-BuLi, THF, $0{ }^{\circ} \mathrm{C}$-rt, 12 h, 76\%. (ii) $\mathrm{PMBCl}, \mathrm{NaH}, \mathrm{DMF}, 0$ ${ }^{\circ} \mathrm{C}, 1 \mathrm{~h}, 94 \%$.

The 1,2-O-isopropylidene group of $\mathbf{3 1}$ was cleaved with $20 \%$ acetic acid and catalytic $\mathrm{H}_{2} \mathrm{SO}_{4}$ to afford the lactol derivative (32). Subsequent Wittig reaction ${ }^{27}$ with $\mathrm{Ph}_{3} \mathrm{P}=\mathrm{CH}_{2}$ to obtain the olefin which was converted in its PMB-ether derivative (11). The structure of (11) was confirmed by its ${ }^{1} \mathrm{H}$ and ${ }^{13} \mathrm{C}$ NMR and mass spectral analysis.

The esterification reaction between 11 and 5-hexenoic acid ${ }^{28}$ (12) was performed under Yamaguchi condition ${ }^{29}$ and deprotection of PMB group gave $\mathbf{1 0}$ which was a precursor for RCM reaction (Scheme 10).

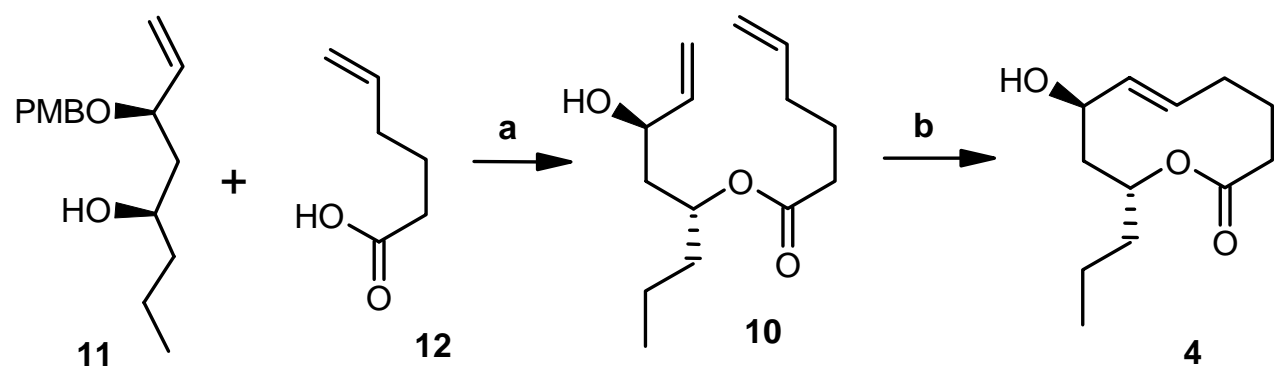

Scheme 10. Reagents and conditions: (a) (i) 2,4,6-trichlorobenzoyl chloride, DMAP, THF, 11 in THF, $0{ }^{\circ} \mathrm{C}$-rt, 4 h, 82\%; (ii) DDQ, $\mathrm{CH}_{2} \mathrm{Cl}_{2} / \mathrm{H}_{2} \mathrm{O}$ (18:1), rt, $30 \mathrm{~min}, 94 \%$. (b) (i) $\mathrm{RuCl}_{2}(=\mathrm{CHPh}$ )$\left(\mathrm{PCy}_{3}\right)_{2}, \mathrm{CH}_{2} \mathrm{Cl}_{2}$, reflux, 4 days, 36\% (52\% starting material recovered), (ii) $\mathrm{RuCl}_{2}(=\mathrm{CHPh}$ ) $\left(\mathrm{PCy}_{3}\right)$ (IEMS), $\mathrm{CH}_{2} \mathrm{Cl}_{2}$, reflux, $16 \mathrm{~h}, 78 \%$.

The RCM of $\mathbf{1 0}$ in the presence of Grubbs' 2nd generation catalyst was efficient and high yielding, thus giving rise to dimmer as a minor product. The structure of $\mathbf{4}$ was confirmed by comparision of spectroscopic and optical rotation with reported values. ${ }^{9}$ 


\section{Conclusions}

In summary, RCM reaction has been judiciously used to complete the total synthesis of medium ring size natural products microcarpalide $\mathbf{1}$ and herbarumin III (4).

\section{Experimental Section}

General Procedures. Solvents were purified and dried by standard procedures before use. Column chromatography was carried out with silica gel (60-120 mesh). Infrared spectra were recorded with Shimadzu IR 420 and Perkin-Elmer 683 spectrometers. NMR spectra were recorded on Bruker AC-200 and Bruker DRX-500 machine in $\mathrm{CDCl}_{3}$ with TMS as internal standard. Mass spectra were obtained with Finningen MAT 1210 mass spectrometer. Optical rotations were measured with digital polarimeter. Elemental analysis was done on elemental analyzer model $1108 \mathrm{EA}$. All reactions were monitored on $0.25 \mathrm{~mm}$ E-Merck pre-coated silica gel (TLC) plates (60F-254) with UV or $\mathrm{I}_{2}$, anisaldehyde reagent in ethanol. Petroleum ether refers to mixture of hexanes with bp $60-80{ }^{\circ} \mathrm{C}$.

\section{2,3-O-Isopropylidene-5,6-dideoxy-7-O-[(2-methoxyethoxy)methyl]- $\alpha$-D-lyxo-heptofuranose} (15). To a solution of compound $13(5.0 \mathrm{~g}, 14.36 \mathrm{mmol})$ in $\mathrm{CH}_{2} \mathrm{Cl}_{2}$ at $-78{ }^{\circ} \mathrm{C}$ was added DIBAL$\mathrm{H}\left(2.5 \mathrm{M}\right.$ toluene solution) $(17.8 \mathrm{~mL}, 35.7 \mathrm{mmol})$. After stirring for $2 \mathrm{~h}$ at $-78{ }^{\circ} \mathrm{C}$, excess DIBAL-H was quenched with saturated sodium potassium tartrate solution. The solid was filtered, the filtrate concentrated and the residue purified on silica gel by eluting with light petroleum: EtOAc (1:1) to give 14 (4.03 g, 92\%), as a colorless liquid. ${ }^{1} \mathrm{H}$ NMR (200 MHz): $\delta$ 1.30 (s, $3 \mathrm{H}), 1.45$ (s, $3 \mathrm{H}), 1.91$ (br s, OH), 4.09-4.23 (m, $3 \mathrm{H}), 4.45-4.53$ (m, $1 \mathrm{H}), 4.58-4.80$ $(\mathrm{m}, 3 \mathrm{H}), 5.07(\mathrm{~m}, 1 \mathrm{H}), 5.71-6.00(\mathrm{~m}, 2 \mathrm{H}), 7.26-7.37(\mathrm{~m}, 5 \mathrm{H}) ;{ }^{13} \mathrm{C}$ NMR $(50 \mathrm{MHz}): \delta 24.5$, 25.8, 58.2, 62.0, 68.5, 68.6, 75.3, 80.1, 81.0, 85.0, 104.8, 111.8, 124.4, 125.2, 127.5, 128.1, 133.3,134.4; Anal. Calcd for $\mathrm{C}_{17} \mathrm{H}_{22} \mathrm{O}_{5}$ : C, 66.65; H, 7.24. Found: C, 66.17; H, 7.09.

The above product ( $3.5 \mathrm{~g}, 11.43 \mathrm{mmol})$, DIPEA ( $3 \mathrm{~mL})$, MEM-Cl (1.6 mL, $13.68 \mathrm{mmol})$ in $\mathrm{CH}_{2} \mathrm{Cl}_{2}(20 \mathrm{~mL})$ were stirred at $\mathrm{rt}$ for $10 \mathrm{~h}$ and concentrated. The residue was dissolved in ethyl acetate, washed with water, brine and dried $\left(\mathrm{Na}_{2} \mathrm{SO}_{4}\right)$. Solvent was evaporated and the residue purified on silica gel by eluting with light petroleum: EtOAc (3:2) to afford $\mathbf{1 4}(3.51 \mathrm{~g}, 78 \%)$ as a colorless liquid. ${ }^{1} \mathrm{H}$ NMR $(200 \mathrm{MHz}): \delta 1.30(\mathrm{~s}, 3 \mathrm{H}), 1.46(\mathrm{~s}, 3 \mathrm{H}), 3.36-3.40(\mathrm{~m}, 4 \mathrm{H}), 3.50-$ 3.62 (m, $3 \mathrm{H}), 3.68-3.75(\mathrm{~m}, 2 \mathrm{H}), 4.15-4.23(\mathrm{~m}, 1 \mathrm{H}), 4.46-4.53(\mathrm{~m}, 1 \mathrm{H}), 4.67$ (s, $2 \mathrm{H}), 4.74-$ 4.76 (m, $2 \mathrm{H}), 5.10$ (s, $2 \mathrm{H}), 5.82-5.95$ (m, $2 \mathrm{H}), 7.26-7.32$ (m, $5 \mathrm{H}) ;{ }^{13} \mathrm{C}$ NMR $(50 \mathrm{MHz}): \delta 24.9$, 26.0, 58.7, 63.2, 66.8, 67.7, 68.7, 71.7, 75.6, 80.3, 81.4, 85.4, 94.5, 94.7, 105.2, 112.4, 126.8, 127.1, 127.6, 127.9, 128.3, 130.1, 131.0, 137.4; Anal. Calcd for $\mathrm{C}_{21} \mathrm{H}_{30} \mathrm{O}_{7}: \mathrm{C}, 63.94 ; \mathrm{H}, 7.67$. Found: C, 64.10; H, 7.19.

The above product $14(3.5 \mathrm{~g}, 8.88 \mathrm{mmol})$ and $10 \% \mathrm{Pd} / \mathrm{C}(100 \mathrm{mg})$ in $\mathrm{MeOH}(40 \mathrm{~mL})$ were stirred under hydrogen at $55 \mathrm{psi}$ at $60{ }^{\circ} \mathrm{C}$ for $4 \mathrm{~h}$ and filtered. The filtrate was concentrated to 
give $15(2.6 \mathrm{~g}, 96 \%)$ as a colorless liquid. ${ }^{1} \mathrm{H}$ NMR $(200 \mathrm{MHz}): \delta 1.30(\mathrm{~s}, 3 \mathrm{H}), 1.43(\mathrm{~s}, 3 \mathrm{H})$, 1.69-1.75 (m, 4 H), 2.87 (br s, OH), 3.38 (s, 3 H), 3.52-3.61 (m, 4 H), 3.65-3.68 (m, 2 H), 4.01$4.17(\mathrm{~m}, 2 \mathrm{H}), 4.54-4.65(\mathrm{~m}, 2 \mathrm{H}), 4.69(\mathrm{~s}, 2 \mathrm{H})$; Anal. Calcd for $\mathrm{C}_{14} \mathrm{H}_{26} \mathrm{O}_{7}$ : C, 54.89; H, 8.55. Found: C, 54.43; H, 8.71.

(2R,3S,4R)-1-(Trimethylacetyl)-2,3-isopropylidenedioxy-4-hydroxy-7-[(2-methoxyethoxy) methoxy]heptanol (16). To a solution of $15(2.5 \mathrm{~g}, 8.16 \mathrm{mmol})$ in THF $(20 \mathrm{~mL})$ at $0{ }^{\circ} \mathrm{C}$ was added $\mathrm{LiAlH}_{4}(0.31 \mathrm{~g}, 8.07 \mathrm{mmol})$ and stirred at $0{ }^{\circ} \mathrm{C}$ for $1 \mathrm{~h}$. Excess of $\mathrm{LiAlH}_{4}$ was quenched by the addition of ethyl acetate. The solid formed was filtered, the filtrate concentrated and purified on silica gel by eluting with light petroleum: EtOAc (1:4) to afford 16 (2.3 g, 92\%) as a colorless liquid. $[\alpha]_{\mathrm{D}}+18.2$ (c 2.8, $\left.\mathrm{CHCl}_{3}\right) ;{ }^{1} \mathrm{H}$ NMR (200 MHz): $\delta$ 1.35-1.48 (2 s, $\left.6 \mathrm{H}\right), 1.57-1.84$ (m, 4 H), 2.25 (br s, OH), 3.37 (s, $3 \mathrm{H}), 3.51-3.57$ (m, $4 \mathrm{H}), 3.63-3.77$ (m, $5 \mathrm{H}), 4.01$ (dd, $1 \mathrm{H}, J=6.8$, $3.4 \mathrm{~Hz}), 4.17(\mathrm{dt}, 1 \mathrm{H}, J=6.8,5.1 \mathrm{~Hz}), 4.68(\mathrm{~s}, 2 \mathrm{H}) ;{ }^{13} \mathrm{C} \mathrm{NMR}(50 \mathrm{MHz}): \delta 24.6,25.6,26.8$, 31.0, 58.4, 60.3, 66.2, 68.25, 71.3, 77.0, 94.9,107.7.

(2R,3R,4R)-2,3-(Isopropylidenedioxy)-4-(tert-butyldimethylsilyloxy)-7-[(2-methoxyethoxy) methoxy]hept-1-ol (17). The above product $16(2.0 \mathrm{~g}, 6.5 \mathrm{mmol})$ in pyridine $(10 \mathrm{~mL})$ under nitrogen at $0{ }^{\circ} \mathrm{C}$ was added trimethylacetyl chloride $(1.2 \mathrm{~mL}, 9.74 \mathrm{mmol})$ drop wise. After stirring for $1 \mathrm{~h}$ at $\mathrm{rt}$, solvent was evaporated, the residue extracted with ethyl acetate and washed with $1 \mathrm{~N} \mathrm{HCl}$, brine, dried $\left(\mathrm{Na}_{2} \mathrm{SO}_{4}\right)$ and evaporated. The residue was purified on silica gel by eluting with petroleum ether: EtOAc (7:3) to give trimethylacetyl protected compound (2.31 g, 91\%) as a colorless liquid. $[\alpha]_{\mathrm{D}}+24.2\left(\mathrm{c} 2.5, \mathrm{CHCl}_{3}\right) ;{ }^{1} \mathrm{H} \mathrm{NMR}(200 \mathrm{MHz}): \delta 1.21(\mathrm{~s}, 9 \mathrm{H}), 1.36-$ $1.48(2 \mathrm{~s}, 6 \mathrm{H}), 1.56-1.83(\mathrm{~m}, 4 \mathrm{H}), 3.39(\mathrm{~s}, 3 \mathrm{H}), 3.52-3.61(\mathrm{~m}, 5 \mathrm{H}), 3.64-3.70(\mathrm{~m}, 2 \mathrm{H}), 4.03(\mathrm{t}$, $1 \mathrm{H}, J=4.8 \mathrm{~Hz}), 4.22-4.30(\mathrm{~m}, 3 \mathrm{H}), 4.7(\mathrm{~s}, 2 \mathrm{H}) ;{ }^{13} \mathrm{C} \mathrm{NMR}(50 \mathrm{MHz}): \delta 23.5,24.6,26.6,26.9$, $30.1,58.2,62.9,66.2,66.9,68.0,71.2,74.5,79.1,94.8,107.8$; Anal. Calcd for $\mathrm{C}_{19} \mathrm{H}_{36} \mathrm{O}_{8}$ : C, 58.14; H, 9.25. Found: C, 57.91; H, 9.18.

A solution of above product $(2.3 \mathrm{~g}, 58.9 \mathrm{mmol})$, imidazole $(0.8 \mathrm{~g}, 11.7 \mathrm{mmol})$ and TBS-Cl $(1.33 \mathrm{~g}, 8.82 \mathrm{mmol})$ in DMF $(10 \mathrm{~mL})$ under nitrogen was stirred at $\mathrm{rt}$ for $4 \mathrm{~h}$. The reaction mixture was diluted with ether, washed with water, dried $\left(\mathrm{Na}_{2} \mathrm{SO}_{4}\right)$ and purified on silica gel by eluting with light petroleum:EtOAc (4:1) to afford TBS-ether (2.6 g, 90\%) as a colorless liquid. $[\alpha]_{\mathrm{D}}+41.1\left(\right.$ c 3.6, $\left.\mathrm{CHCl}_{3}\right) ;{ }^{1} \mathrm{H}$ NMR $(200 \mathrm{MHz}): \delta-0.05(\mathrm{~s}, 6 \mathrm{H}), 0.87(\mathrm{~s}, 9 \mathrm{H}), 1.31-1.43(2 \mathrm{~s}, 6$ H), 1.51-1.85 (m, $4 \mathrm{H}), 3.37$ (s, $3 \mathrm{H}), 3.49-3.55$ (m, $4 \mathrm{H}), 3.62-3.76$ (m, $3 \mathrm{H}), 3.99$ (dd, $4 \mathrm{H}, J=$ 8.1, $5.4 \mathrm{~Hz}), 4.67$ (s, $2 \mathrm{H}) ;{ }^{13} \mathrm{C}$ NMR (50 MHz): $\delta-4.8,-4.3,18.0,25.2,25.7,26.8,27.58,30.46$, $38.29,58.4,62.9,66.3,67.0,70.0,71.4,74.6,80.2,95.0,107.9,177.4$.

To the above product $(2.5 \mathrm{~g}, 6.39 \mathrm{mmol})$ in $\mathrm{CH}_{2} \mathrm{Cl}_{2}(20 \mathrm{~mL})$ under nitrogen and at $-78{ }^{\circ} \mathrm{C}$ was added DIBAL-H (2.6 M in toluene, $6.2 \mathrm{~mL}, 62.6 \mathrm{mmol})$ drop wise. After $1 \mathrm{~h}$, excess of DIBAL-H was quenched by using saturated aqueous sodium potassium tartrate solution. The organic layer was separated out and the aqueous layer extracted with $\mathrm{CH}_{2} \mathrm{Cl}_{2}$. The combined organic layer was washed with brine, dried over $\mathrm{Na}_{2} \mathrm{SO}_{4}$ and concentrated to afford the crude product which was purified on silica gel by using light petroleum:EtOAc (1:1) to give 17 (1.9 g, $89 \%$ ) as a colorless liquid. $[\alpha]_{\mathrm{D}}+56.3\left(\mathrm{c} \mathrm{3.1,} \mathrm{CHCl}_{3}\right) ;{ }^{1} \mathrm{H} \mathrm{NMR}(200 \mathrm{MHz}): \delta-0.05(\mathrm{~s}, 6 \mathrm{H}), 0.87$ (s, 9 H), 1.31-1.43 (2 s, 6 H), 1.51-1.72 (m, 4 H), 2.25 (br s, OH), 3.37 (s, 3 H), 3.48-3.76 (m, 9 
$\mathrm{H}), 3.98-4.18(\mathrm{~m}, 2 \mathrm{H}), 4.67$ (s, $2 \mathrm{H}) ;{ }^{13} \mathrm{C} \mathrm{NMR}(50 \mathrm{MHz}): \delta-4.8,-4.3,18.0,25.0,25.7,27.8$, 30.5 , 58.4, 60.9, 66.3, 67.1, 70.0, 71.4, 77.4, 80.2, 95.0,107.8; Anal. Calcd for $\mathrm{C}_{20} \mathrm{H}_{42} \mathrm{O}_{7} \mathrm{Si}$ : C, 56.84; H, 10.02. Found: C, 56.79; H, 9.98.

\section{(2S,3R,4R)-1-Iodo-2,3-isopropylidenedioxy-4-tert-butyldimethylsilyloxy-7-[(2-} methoxyethoxy )methoxy)]heptane (7) and (2S, 3R)-1,4-anhydro-2,3-isopropylidenedioxy-7[(2-methoxy- ethoxy)methoxy]heptitol (18). A mixture of 17 (0.5 g, $2.82 \mathrm{~mol}), \mathrm{PPh}_{3}(0.46 \mathrm{~g}$, $1.76 \mathrm{mmol})$, imidazole $(0.12 \mathrm{~g}, 1.76 \mathrm{mmol})$ and $\mathrm{Et}_{3} \mathrm{~N}(0.25 \mathrm{~mL})$ in $\mathrm{CH}_{2} \mathrm{Cl}_{2}$ was stirred at $\mathrm{rt}$ under nitrogen for $2.5 \mathrm{~h}$. The reaction mixture was diluted with $\mathrm{CH}_{2} \mathrm{Cl}_{2}$, washed with $20 \%$ aqueous $\mathrm{Na}_{2} \mathrm{~S}_{2} \mathrm{O}_{3}$ solution, brine, dried $\left(\mathrm{Na}_{2} \mathrm{SO}_{4}\right)$, evaporated. The residue was purified on silica gel by eluting with light petroleum: EtOAc (4:1) to obtain 7 (0.28 g, 45\%). [ $\alpha]_{\mathrm{D}}+84.8$ (c 2.2, $\mathrm{CHCl}_{3}$ ); ${ }^{1} \mathrm{H}$ NMR $(200 \mathrm{MHz}): \delta-0.07$ (s, $\left.6 \mathrm{H}\right), 0.88$ (s, $\left.9 \mathrm{H}\right), 1.34-1.49(2 \mathrm{~s}, 6 \mathrm{H}), 1.53-1.83$ (m, $\left.4 \mathrm{H}\right), 3.12$ $(\mathrm{t}, 1 \mathrm{H}, J=10.4 \mathrm{~Hz}), 3.27(\mathrm{dd}, 1 \mathrm{H}, J=10.4,3.3 \mathrm{~Hz}), 3.4(\mathrm{~s}, 3 \mathrm{H}), 3.52-3.58(\mathrm{~m}, 4 \mathrm{H}), 3.65-3.70$ $(\mathrm{m}, 2 \mathrm{H}), 3.78-3.81(\mathrm{~m}, 1 \mathrm{H}), 3.93(\mathrm{dd}, 1 \mathrm{H}, J=8.2,5.3 \mathrm{~Hz}), 4.22(\mathrm{~m}, 1 \mathrm{H}), 4.7(\mathrm{~s}, 2 \mathrm{H}) ;{ }^{13} \mathrm{C}$ NMR (50 MHz): $\delta-4.9,-4.4,5.6,18.0,25.2,25.6,27.8,30.2,58.4,66.3,66.8,70.0,71.3,77.0$, 80.2, 94.9; Anal. Calcd for $\mathrm{C}_{20} \mathrm{H}_{41} \mathrm{IO}_{6} \mathrm{Si}: \mathrm{C}, 45.11$; H, 7.76. Found: C, 44.98; H, 7.58.

Further elution gave $18(0.015 \mathrm{~g}, 15 \%)$. $[\alpha]_{\mathrm{D}}+32.2\left(\mathrm{c} 1, \mathrm{CHCl}_{3}\right) ;{ }^{1} \mathrm{H} \mathrm{NMR}(200 \mathrm{MHz}): \delta$ $1.30(\mathrm{~s}, 3 \mathrm{H}), 1.46$ (s, $3 \mathrm{H}), 1.65-1.81(\mathrm{~m}, 4 \mathrm{H}), 3.38$ (s, $3 \mathrm{H}), 3.43-3.47$ (m, $2 \mathrm{H}), 3.52-3.60$ (m, 4 $\mathrm{H}), 3.64-3.70(\mathrm{~m}, 2 \mathrm{H}), 3.96(\mathrm{~d}, 1 \mathrm{H}, J=10.6 \mathrm{~Hz}), 4.5(\mathrm{dd}, 1 \mathrm{H}, J=6.3,3.7 \mathrm{~Hz}), 4.7(\mathrm{~s}, 2 \mathrm{H})$, $4.73\left(\mathrm{dd}, 1 \mathrm{H}, J=6.3,3.7 \mathrm{~Hz}\right.$ ); Anal. Calcd for $\mathrm{C}_{14} \mathrm{H}_{26} \mathrm{O}_{6}: \mathrm{C}, 57.91$; H, 9.03. Found: C, 57.79; $\mathrm{H}$, 9.12 .

(3R,4R)-4-(tert-Butyldimethylsilyloxy)-7-[(2-methoxyethoxy)methoxy]hept-1-en-3-ol (19). A mixture of $7(1.5 \mathrm{~g}, 2.82 \mathrm{mmol})$, Zinc $(0.36 \mathrm{~g}, 5.64 \mathrm{mmol})$ in refluxing ethanol $(15 \mathrm{~mL})$ was stirred for $1.5 \mathrm{~h}$ and filtered. The filtrate was concentrated, and then purified on silica gel by using light petroleum: EtOAc (7:3) to obtain $19(0.96 \mathrm{~g}, 96 \%)$ as an oil. $[\alpha]_{\mathrm{D}}+72.7(\mathrm{c} 0.75$, $\left.\mathrm{CHCl}_{3}\right) ;{ }^{1} \mathrm{H}$ NMR $(200 \mathrm{MHz}): \delta-0.65(\mathrm{~s}, 6 \mathrm{H}), 0.89(\mathrm{~s}, 9 \mathrm{H}), 1.56-1.69(\mathrm{~m}, 4 \mathrm{H}), 2.38(\mathrm{~d}, \mathrm{OH}, J=$ $6.3 \mathrm{~Hz}), 3.40$ (s, $3 \mathrm{H}), 3.51-3.61(\mathrm{~m}, 5 \mathrm{H}), 3.70$ (ddd, $2 \mathrm{H}, J=5.4,3.5,1.1 \mathrm{~Hz}), 3.95-4.04$ (m, 1 $\mathrm{H}), 4.71(\mathrm{~s}, 2 \mathrm{H}), 5.19(\mathrm{dt}, 1 \mathrm{H}, J=10.2,1.5 \mathrm{~Hz}), 5.31(\mathrm{dt}, 1 \mathrm{H}, J=17.3,1.5 \mathrm{~Hz}), 5.84(\mathrm{ddd}, 1 \mathrm{H}$, $J=17.3,10.2,5.3 \mathrm{~Hz}) ;{ }^{13} \mathrm{C}$ NMR (50 MHz): $\delta-4.9,17.5,25.0,25.4,58.2,66.0,67.2,71.2,73.8$, 74.5, 94.7, 114.7, 137.8; Anal. Calcd for $\mathrm{C}_{17} \mathrm{H}_{36} \mathrm{O}_{5} \mathrm{Si}$ : C, 58.58; H, 10.41. Found: C, 58.23; H, 10.15 .

$(4 R, 5 R)-4,5-B i s-b e n z y l o x y-7-[(2-m e t h o x y e t h o x y) m e t h o x y] h e p t-1-e n e ~(20)$. A solution of 19 $(2.0 \mathrm{~g}, 5.7 \mathrm{mmol})$ and $1 \mathrm{M}$ solution of $\mathrm{Bu}_{4} \mathrm{NF}(5.7 \mathrm{~mL}, 5.7 \mathrm{mmol})$ in THF $(10 \mathrm{~mL})$ was stirred at $\mathrm{rt}$ for $1 \mathrm{~h}$ and evaporated. The residue was purified on silica gel by eluting with light petroleum: EtOAc (3:7) to give diol $(1.31 \mathrm{~g}, 85 \%)$, as a colorless liquid. $[\alpha]_{\mathrm{D}}+24.5\left(c 0.9, \mathrm{CHCl}_{3}\right) ;{ }^{1} \mathrm{H} \mathrm{NMR}$ (200 MHz): $\delta 1.52-1.81(\mathrm{~m}, 4 \mathrm{H}), 3.39(\mathrm{~s}, 3 \mathrm{H}), 3.44-3.62(\mathrm{~m}, 5 \mathrm{H}), 3.65-3.71(\mathrm{~m}, 2 \mathrm{H}), 3.89(\mathrm{t}$, $1 \mathrm{H}, J=1.3 \mathrm{~Hz}), 4.71(\mathrm{~s}, 2 \mathrm{H}), 5.22(\mathrm{dt}, 1 \mathrm{H}, J=10.2,1.4 \mathrm{~Hz}), 5.34$ (dt, $1 \mathrm{H}, J=17.2,1.4 \mathrm{~Hz})$, 5.84 (ddd, $1 \mathrm{H}, J=17.2,10.5,6.5 \mathrm{~Hz}) ;{ }^{13} \mathrm{C} \mathrm{NMR}(50 \mathrm{MHz}): \delta 25.5,29.9,58.5,66.4,67.5,71.4$, 73.8, 75.9, 95.0, 116.5, 137.6 .

To the above product $(1.5 \mathrm{~g}, 6.41 \mathrm{mmol})$ in DMF $(10 \mathrm{~mL})$ at $0{ }^{\circ} \mathrm{C}$ was added $\mathrm{NaH}(60 \%$ dispersion in mineral oil (0.56 g, $14 \mathrm{mmol})$. After $15 \mathrm{~min}$, benzyl bromide $(1.7 \mathrm{~mL}, 14 \mathrm{mmol})$ 
was introduced and the reaction stirred for $2 \mathrm{~h}$ at rt. Water was carefully added to the reaction mixture, extracted with ether, washed with water and dried $\left(\mathrm{Na}_{2} \mathrm{SO}_{4}\right)$. On evaporation of solvent, the residue was purified by silica gel column chromatography by eluting with light petroleum:EtOAc (1:9) to afford $19(2.34 \mathrm{~g}, 88 \%)$ as a colorless liquid. $[\alpha]_{\mathrm{D}}+8.9\left(\mathrm{c} 1.4, \mathrm{CHCl}_{3}\right)$; ${ }^{1} \mathrm{H}$ NMR (200 MHz): $\delta$ 1.44-1.76 (m, $\left.4 \mathrm{H}\right), 3.39$ (s, $\left.3 \mathrm{H}\right), 3.47-3.55$ (m, $\left.5 \mathrm{H}\right), 3.63-3.68$ (m, 2 H), $3.9(\mathrm{t}, 1 \mathrm{H}, J=6.4 \mathrm{~Hz}), 4.25(\mathrm{~d}, 1 \mathrm{H}, J=12.1 \mathrm{~Hz}), 4.55(\mathrm{~d}, 1 \mathrm{H}, J=11.4 \mathrm{~Hz}), 4.65(\mathrm{~d}, 1 \mathrm{H}, J$ $=12.1 \mathrm{~Hz}), 4.68(\mathrm{~s}, 2 \mathrm{H}), 4.76(\mathrm{~d}, 1 \mathrm{H}, J=11.4 \mathrm{~Hz}), 5.25-5.35(\mathrm{~m}, 2 \mathrm{H}), 5.82(\mathrm{ddd}, 1 \mathrm{H}, J=$

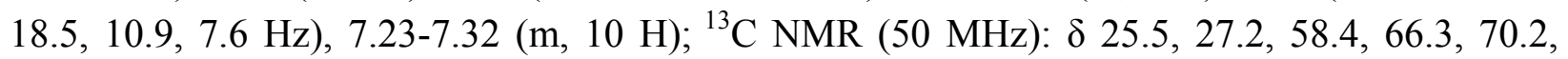
$71.5,72.7,80.6,82.2$, 95.0, 118.0,127.0, 127.3, 127.5, 127.9, 135.1, 138.3, 138.6; Anal. Calcd for $\mathrm{C}_{25} \mathrm{H}_{34} \mathrm{O}_{5}$ : C, 72.43; H, 8.27. Found: C, 72.18; H, 8.13.

(4R,5R)-4,5-Bis-benzyloxy-hept-6-enoic acid (5). A solution of 20 (0.9 g, $2.11 \mathrm{mmol})$ and PPTS $(5.27 \mathrm{~g}, 21 \mathrm{mmol})$ in $t-\mathrm{BuOH}(20 \mathrm{~mL})$ was heated at $80{ }^{\circ} \mathrm{C}$ for $1.5 \mathrm{~h}$. Solvent was removed, residue extracted with ethyl acetate, washed with water, brine, dried $\left(\mathrm{Na}_{2} \mathrm{SO}_{4}\right)$, evaporated. The residue was purified on silica gel by eluting with EtOAc:light petroleum (2:3) to give 21 (0.59 g, $85 \%)$ as a colorless liquid. $[\alpha]_{\mathrm{D}}+10.4\left(c \mathrm{1.3}, \mathrm{CHCl}_{3}\right) ;{ }^{1} \mathrm{H} \mathrm{NMR}(200 \mathrm{MHz}): \delta 1.43-1.70(\mathrm{~m}, 4 \mathrm{H})$, 1.83 (s, OH), 3.46-3.57 (m, $3 \mathrm{H}), 3.93$ (t, $1 \mathrm{H}, J=6.4 \mathrm{~Hz}), 4.38(\mathrm{~d}, 1 \mathrm{H}, J=11.9 \mathrm{~Hz}), 4.54(\mathrm{~d}, 1$ $\mathrm{H}, J=11.4 \mathrm{~Hz}), 4.63(\mathrm{~d}, 1 \mathrm{H}, J=11.9 \mathrm{~Hz}), 4.75(\mathrm{~d}, 1 \mathrm{H}, J=11.4 \mathrm{~Hz}), 5.25-5.35(\mathrm{~m}, 2 \mathrm{H}), 5.8$ (ddd, $1 \mathrm{H}, J=16.6,10.8,7.5 \mathrm{~Hz}), 7.22-7.31(\mathrm{~m}, 10 \mathrm{H}) ;{ }^{13} \mathrm{C}$ NMR $(50 \mathrm{MHz}): \delta 27.1,28.7,62.3$, 70.4, 73.0, 80.9, 82.2, 118.6,121.7-128.1 (m), 135.1, 138.3, 138.4.

The above product $(0.52 \mathrm{~g}, 1.59 \mathrm{mmol})$ in $\mathrm{CH}_{2} \mathrm{Cl}_{2}(3 \mathrm{~mL})$ was added to a stirred solution of DMSO $(0.34 \mathrm{~mL}, 4.76 \mathrm{mmol})$ and $(\mathrm{COCl})_{2}(0.17 \mathrm{~mL}, 1.98 \mathrm{mmol})$ in $\mathrm{CH}_{2} \mathrm{Cl}_{2}(5 \mathrm{~mL})$ at $-78{ }^{\circ} \mathrm{C}$ under nitrogen. The reaction was stirred for $30 \mathrm{~min}$, quenched and worked up in the usual fashion to give a residue which was stirred with aq. $\mathrm{NaClO}_{2}(0.19 \mathrm{~g}$ in $2 \mathrm{~mL}$ water, $2.08 \mathrm{mmol})$ DMSO $(2 \mathrm{~mL}), \mathrm{NaH}_{2} \mathrm{PO}_{4}(0.16 \mathrm{~g}, 1.05 \mathrm{mmol})$. After $2 \mathrm{~h}$, the reaction mixture was diluted with water, extracted with EtOAc, dried $\left(\mathrm{Na}_{2} \mathrm{SO}_{4}\right)$, concentrated. The residue was passed througha column of silica gel by eluting with light petroleum:EtOAc $(9: 1)$ to give $5(0.43 \mathrm{~g}, 90 \%)$ as a colorless liquid. $[\alpha]_{\mathrm{D}}+16.8\left(\mathrm{c} 0.7, \mathrm{CHCl}_{3}\right) ;{ }^{1} \mathrm{H}$ NMR $(200 \mathrm{MHz}): \delta 1.61-1.80(\mathrm{~m}, 1 \mathrm{H}), 1.83-$ $1.99(\mathrm{~m}, 1 \mathrm{H}), 2.33-2.44(\mathrm{~m}, 2 \mathrm{H}), 3.52(\mathrm{ddd}, 1 \mathrm{H}, J=9.3,6.0,3.7 \mathrm{~Hz}), 3.90(\mathrm{t}, 1 \mathrm{H}, J=6.5 \mathrm{~Hz})$, $4.38(\mathrm{~d}, 1 \mathrm{H}, J=12.2 \mathrm{~Hz}), 4.52(\mathrm{~d}, 1 \mathrm{H}, J=11.3 \mathrm{~Hz}), 4.64(\mathrm{~d}, 1 \mathrm{H}, J=12.1 \mathrm{~Hz}), 4.76(\mathrm{~d}, 1 \mathrm{H}, J=$ $11.3 \mathrm{~Hz}$ ), 5.32 (br dd, $1 \mathrm{H}, J=18.4,1.7 \mathrm{~Hz}$ ), 5.36 (br dd, $1 \mathrm{H}, J=9.1,1.8 \mathrm{~Hz}$ ), 5.81 (br ddd, $1 \mathrm{H}$, $J=18.3,10.9,7.5 \mathrm{~Hz}), 7.25-7.33(\mathrm{~m}, 10 \mathrm{H}) ;{ }^{13} \mathrm{C}$ NMR $(50 \mathrm{MHz}): \delta 26.3,30.9,70.5,73.3,80.2$, 82.7, 96.1, 118.8, 127.4, 127.6, 127.9, 135.1, 138.6, 178.7; Anal. Calcd for $\mathrm{C}_{15} \mathrm{H}_{30} \mathrm{O}_{4}$ : C, 65.66; H, 11.02. Found: C, 65.07; H, 10.83 .

Ethyl (2R,3S)-2,3-Dihydroxy nonoate (23). To a mixture of $\mathrm{K}_{3}\left[\mathrm{Fe}(\mathrm{CN})_{6}\right](26.67 \mathrm{~g}, 81.2 \mathrm{mmol})$, $\mathrm{K}_{2} \mathrm{CO}_{3}(11.2 \mathrm{~g}, 81.2 \mathrm{mmol})$, (DHQ) 2 PHAL (0.211g, $\left.0.27 \mathrm{mmol}\right), \mathrm{MeSO}_{2} \mathrm{NH}_{2}(2.57 \mathrm{~g}, 27.1$ $\mathrm{mmol})$ and $\mathrm{K}_{2} \mathrm{OsO}_{4} \cdot 2 \mathrm{H}_{2} \mathrm{O}(0.211 \mathrm{~g}, 0.1 \mathrm{mmol})$ in $t-\mathrm{BuOH}_{2} \mathrm{H}^{-}{ }_{2} \mathrm{O}$ (200 mL total volume, $1: 1$ mixture) at $0{ }^{\circ} \mathrm{C}$ was added olefin $9(5 \mathrm{~g}, 27.1 \mathrm{mmol})$ and stirred at $0{ }^{\circ} \mathrm{C}$. After $10 \mathrm{~h}$, sodium sulphite (10.2 g) was added, solvent removed under vacuum. The residue was extracted with ethyl acetate, washed with $2 \mathrm{~N} \mathrm{KOH}$, water, brine, dried $\left(\mathrm{Na}_{2} \mathrm{SO}_{4}\right)$ and evaporated. The residue on purification by silica gel chromatography by eluting with light petroleum: EtOAc (4:1) to 
afford the diol $23(5.56 \mathrm{~g}, 94 \%)$ as a colorless liquid. $[\alpha]_{\mathrm{D}}-10.7$ (c 1.0, $\left.\mathrm{CHCl}_{3}\right) ;{ }^{1} \mathrm{H}$ NMR $(200$ $\mathrm{MHz}): \delta 0.87(\mathrm{t}, 3 \mathrm{H}, J=6.6 \mathrm{~Hz}), 1.21-1.38(\mathrm{~m}, 8 \mathrm{H}), 1.44-1.51(\mathrm{~m}, 2 \mathrm{H}), 1.56(\mathrm{t}, 3 \mathrm{H}, J=7.4$ Hz), 2.50 (br.s, OH), 3.88 (dt, $1 \mathrm{H}, J=6.4,2.1 \mathrm{~Hz}), 4.08(\mathrm{~d}, 1 \mathrm{H}, J=2.1 \mathrm{~Hz}), 4.28(\mathrm{q}, 2 \mathrm{H}, J=$ $7.4 \mathrm{~Hz}) ;{ }^{13} \mathrm{C}$ NMR (50 MHz): $\delta 13.8,22.3,25.5,29.0,31.5,33.2,61.5,72.4,73.3,173.5$; Anal. Calcd for $\mathrm{C}_{11} \mathrm{H}_{22} \mathrm{O}_{4}$ : C, 60.52; $\mathrm{H}, 10.16$. Found: $\mathrm{C}, 60.27 ; \mathrm{H}, 10.43$.

(2R,3S)-2,3-(Isopropilidenedioxy)-1-(p-toluene sulphonyl) nonane (24). A solution of 23 (5.5 g, $25.2 \mathrm{mmol})$, 2,2-dimethoxypropane $(3.7 \mathrm{~mL}, 30.27 \mathrm{mmol})$ and catalytic $p$-TSA in $\mathrm{CH}_{2} \mathrm{Cl}_{2}(50$ $\mathrm{mL}$ ) was stirred at room temperature for $4 \mathrm{~h}$. It was diluted with $\mathrm{CH}_{2} \mathrm{Cl}_{2}$, washed with $\mathrm{NaHCO}_{3}$, water, brine, concentrated and purified by silica gel chromatography by using light petroleum: EtOAc (9:1) to afford protected product $(6.26 \mathrm{~g}, 96 \%)$ as a colorless liquid. $[\alpha]_{\mathrm{D}}-17.6$ (c 1.4, $\left.\mathrm{CHCl}_{3}\right) ;{ }^{1} \mathrm{H}$ NMR $(200 \mathrm{MHz}): \delta 0.89(\mathrm{t}, 3 \mathrm{H}, J=6.4 \mathrm{~Hz}), 1.21-1.42(\mathrm{~m}, 10 \mathrm{H}), 1.40-1.43(2 \mathrm{~s}, 6$ $\mathrm{H}), 1.57$ (t, $3 \mathrm{H}, J=7.4 \mathrm{~Hz}), 4.05-4.12(\mathrm{~m}, 2 \mathrm{H}), 4.25$ (q, $2 \mathrm{H}, J=7.4 \mathrm{~Hz}) ;{ }^{13} \mathrm{C} \mathrm{NMR}(50 \mathrm{MHz})$ : $\delta$ 13.6, 22.2, 25.2, 28.8, 31.3, 33.2, 61.0, 78.9, 110.3,170.5; Anal. Calcd for $\mathrm{C}_{14} \mathrm{H}_{26} \mathrm{O}_{4}$ : C, 65.09; H, 10.14. Found: C, 64.87; H, 10.37 .

To a solution of above product $(5.2 \mathrm{~g}, 20.1 \mathrm{mmol})$ in $\mathrm{CH}_{2} \mathrm{Cl}_{2}(50 \mathrm{~mL})$ at $-78{ }^{\circ} \mathrm{C}$ was added DIBAL-H (2.5 M solution in toluene, $20 \mathrm{~mL}, 50 \mathrm{mmol})$. After stirring at $-78^{\circ} \mathrm{C}$ for $1 \mathrm{~h}$, excess of DIBAL-H was quenched by the addition of saturated aqueous sodium potassium tartarate. The solid was filtered, filtrate concentrated and the residue purified on silica gel eluting with light petroleum: EtOAc (3:2) to give alcohol (4.2 g, 97\%) as a colorless liquid. $[\alpha]_{\mathrm{D}}-24.5$ (c 1.1, $\left.\mathrm{CHCl}_{3}\right) ;{ }^{1} \mathrm{H}$ NMR $(200 \mathrm{MHz}): \delta 0.86(\mathrm{t}, 3 \mathrm{H}, J=6.2 \mathrm{~Hz}), 1.26-1.37(\mathrm{~m}, 8 \mathrm{H}), 1.39-1.40(2 \mathrm{~s}, 6$ H), 1.46-1.59 (m, 2 H), 1.8 (br s, OH), 3.53 (dd, $1 \mathrm{H}, J=11.3,3.8 \mathrm{~Hz}), 3.67$ (m, 2 H), 3.81-3.91 $(\mathrm{m}, 1 \mathrm{H}) ;{ }^{13} \mathrm{C}$ NMR $(50 \mathrm{MHz}): \delta 13.8,22.4,25.8,26.9,27.2,29.2,31.6,33.0,62.2,77.2,81.9$, 108.4.27.1, 28.7, 62.3, 70.4, 73.0, 80.9; Anal. Calcd for $\mathrm{C}_{12} \mathrm{H}_{24} \mathrm{O}_{3}$ : C, 66.63; H, 11.18. Found: C, $66.81 ; \mathrm{H}, 10.98$.

Above product (4.1 g, $19.0 \mathrm{mmol}), \mathrm{TsCl}(4.43 \mathrm{~g}, 22.76 \mathrm{mmol})$ and pyridine $(20 \mathrm{~mL})$ were stirred at $\mathrm{rt}$ for $7 \mathrm{~h}$. Pyridine was removed under vacuum and the residue extracted with EtOAc, washed with $1 \mathrm{~N} \mathrm{HCl}$, water, brine, dried $\left(\mathrm{Na}_{2} \mathrm{SO}_{4}\right)$ and evaporated. The residue was purified by silica gel column chromatography by eluting with light petroleum: EtOAc (4:1) to give 24 (6.74 g, $96 \%)$ as a colorless liquid. $\left.[\alpha]_{\mathrm{D}}-16.4(c) 3.6, \mathrm{CHCl}_{3}\right) ;{ }^{1} \mathrm{H} \mathrm{NMR}(200 \mathrm{MHz}): \delta 0.89(\mathrm{t}, 3 \mathrm{H}, J=6.9$ $\mathrm{Hz}), 1.27-1.31(\mathrm{~m}, 11 \mathrm{H}), 1.37$ (s, $3 \mathrm{H}), 1.46-1.58(\mathrm{~m}, 2 \mathrm{H}), 2.46$ (s, $3 \mathrm{H}), 3.77-3.81(\mathrm{~m}, 2 \mathrm{H})$, 4.07-4.11 (m, $2 \mathrm{H}), 7.35(\mathrm{~d}, 2 \mathrm{H}, J=8.2 \mathrm{~Hz}), 7.81(\mathrm{~d}, 2 \mathrm{H}, J=8.2 \mathrm{~Hz}) ;{ }^{13} \mathrm{C} \mathrm{NMR}(50 \mathrm{MHz}): \delta$ 13.3, 20.7, 21.7, 25.0, 25.6, 26.5, 28.4, 30.9, 32.3, 68.6, 76.0, 77.5, 108.3, 127.2, 129.1, 132.4,144.2; Anal. Calcd for $\mathrm{C}_{21} \mathrm{H}_{30} \mathrm{O}_{5} \mathrm{~S}: \mathrm{C}, 63.93$; H, 7.66, S, 8.13. Found: C, 63.79; H, 7.83, S, 8.32 .

(2S)-2-[1-\{(1S)-(2-Methoxyethoxy)methoxy\}heptyl]oxirane (8). To a solution of 24 (6.5 g, $17.56 \mathrm{mmol})$ in $\mathrm{MeOH}(30 \mathrm{~mL})$ was added $\mathrm{HCl}$ (cat.) and the mixture was stirred at room temperature for $3 \mathrm{~h}$. Solvent was removed in vacuum and the residue extracted with EtOAc, washed with water, brine, dried $\left(\mathrm{Na}_{2} \mathrm{SO}_{4}\right)$ and evaporated. The residue was purified by silica gel chromatography eluting with light petroleum: EtOAc $(3: 2)$ to afford diol $(5.1 \mathrm{~g}, 87 \%)$ as a colorless liquid. $[\alpha]_{\mathrm{D}}-23.41\left(c \mathrm{1} .6, \mathrm{CHCl}_{3}\right) ;{ }^{1} \mathrm{H} \mathrm{NMR}(200 \mathrm{MHz}): \delta 0.88(\mathrm{t}, 3 \mathrm{H}, J=6.5 \mathrm{~Hz})$, 
$1.27(\mathrm{~m}, 8 \mathrm{H}), 1.41-1.53(\mathrm{~m}, 2 \mathrm{H}), 2.05$ (br s, OH), 2.46 (s, $3 \mathrm{H}), 3.55-3.63(\mathrm{~m}, 1 \mathrm{H}), 3.70-3.76$ $(\mathrm{m}, 1 \mathrm{H}), 4.09(\mathrm{dd}, 2 \mathrm{H}, J=4.9,3.3 \mathrm{~Hz}), 7.36(\mathrm{~d}, 2 \mathrm{H}, J=8.4 \mathrm{~Hz}), 7.81(\mathrm{~d}, 2 \mathrm{H}, J=8.4 \mathrm{~Hz}) ;{ }^{13} \mathrm{C}$ NMR (50 MHz): $\delta 13.8,21.4,22.3,25.3,29.0,29.2,31.5,33.1,70.6,71.3,128.0,129.8,132.4$, 144.9; Anal. Calcd for $\mathrm{C}_{16} \mathrm{H}_{26} \mathrm{O}_{5} \mathrm{~S}$ : C, 58.16; H, 7.93, S, 9.70. Found: C, 58.33; H, 8.08; S, 9.86.

Above product $(5.0 \mathrm{~g}, 15.13 \mathrm{mmol})$ was dissolved in $\mathrm{MeOH}(30 \mathrm{~mL})$ and $\mathrm{K}_{2} \mathrm{CO}_{3}(3.13 \mathrm{~g}$, $22.68 \mathrm{mmol}$ ) was added. The mixture was stirred at room temperature for $1.5 \mathrm{~h}$ and concentrated. The residue was dissolved in water and extracted with ethyl acetate, washed with water, dried $\left(\mathrm{Na}_{2} \mathrm{SO}_{4}\right)$ and evaporated. Purification on silica gel using light petroleum: EtOAc $(4: 1)$ as an eluent afforded pure epoxide $(2.03 \mathrm{~g}, 85 \%)$ as a colorless liquid. $[\alpha]_{\mathrm{D}}-5.0\left(\mathrm{c} 1.2, \mathrm{CHCl}_{3}\right) ;{ }^{1} \mathrm{H}$ NMR (200 MHz, $\left.\mathrm{CDCl}_{3}\right): \delta 0.96(\mathrm{t}, 3 \mathrm{H}, J=6.4 \mathrm{~Hz}), 1.24-1.41(\mathrm{~m}, 8 \mathrm{H}), 1.56-1.64(\mathrm{~m}, 2 \mathrm{H})$, $2.72(\mathrm{dd}, 1 \mathrm{H}, J=4.9,2.5 \mathrm{~Hz}), 2.82(\mathrm{t}, 1 \mathrm{H}, J=4.9 \mathrm{~Hz}), 2.97(\mathrm{dt}, 1 \mathrm{H}, J=6.8,2.5 \mathrm{~Hz}), 3.43$ (br m, $1 \mathrm{H}) ;{ }^{13} \mathrm{C}$ NMR (50 MHz): $\delta$ 13.8, 22.4, 25.1, 29.1, 29.2, 31.6, 34.1, 45.0, 55.5, 71.7; Anal. Calcd for $\mathrm{C}_{9} \mathrm{H}_{18} \mathrm{O}_{2}$ : C, 68.31; H, 11.47. Found: C, 68.08; H, 11.73.

A mixture of above product $(2.0 \mathrm{~g}, 12.6 \mathrm{mmol}), \mathrm{MEM}-\mathrm{Cl}(1.73 \mathrm{~mL}, 15.17 \mathrm{mmol})$ and DIPEA $(3.28 \mathrm{~mL}, 18.97 \mathrm{mmol})$ in $\mathrm{CH}_{2} \mathrm{Cl}_{2}(15 \mathrm{~mL})$ were stirred at room temperature for $4 \mathrm{~h}$ and concentrated. The residue was extracted with ethyl acetate, washed with water, dried $\left(\mathrm{Na}_{2} \mathrm{SO}_{4}\right)$, evaporated and was purified by silica gel chromatography using light petroleum: EtOAc (4:1) to afford $8(2.83 \mathrm{~g}, 91 \%)$ as a colorless liquid. $[\alpha]_{\mathrm{D}}-41.06\left(c\right.$ 1.7, $\left.\mathrm{CHCl}_{3}\right) ;{ }^{1} \mathrm{H} \mathrm{NMR}(200 \mathrm{MHz}): \delta$ $0.87(\mathrm{t}, 3 \mathrm{H}, J=6.4 \mathrm{~Hz}), 1.2-1.36(\mathrm{~m}, 8 \mathrm{H}), 1.55-1.62(\mathrm{~m}, 2 \mathrm{H}), 2.5$ (dd, $1 \mathrm{H}, J=4.9,2.6 \mathrm{~Hz})$, $2.74(\mathrm{dd}, 1 \mathrm{H}, J=4.9,3.9 \mathrm{~Hz}), 2.93(\mathrm{ddd}, 1 \mathrm{H}, J=7.0,4.2,2.7 \mathrm{~Hz}), 3.22-3.32(\mathrm{~m}, 1 \mathrm{H}), 3.37$ (s, $3 \mathrm{H}), 3.51-3.77(\mathrm{~m}, 4 \mathrm{H}), 4.73(\mathrm{~d}, 1 \mathrm{H}, J=6.9 \mathrm{~Hz}), 4.92(\mathrm{~d}, 1 \mathrm{H}, J=6.9 \mathrm{~Hz}) ;{ }^{13} \mathrm{C}$ NMR $(50$ $\mathrm{MHz}): \delta 13.3,21.8,24.6,28.6,31.0,42.6,53.7,57.9,66.2,71.0,77.0,93.5$; Anal. Calcd for $\mathrm{C}_{13} \mathrm{H}_{26} \mathrm{O}_{4}$ : C, 63.38; H, 10.64. Found: C, 63.28; H, 10.23.

(4S,5S)-5-[(2-Methoxyethoxy)methoxy]undec-1-en-4-ol (6). To a solution of 8 (1.5 g, 6.08 $\mathrm{mmol})$ in DMSO $(5 \mathrm{~mL})$ at $0{ }^{\circ} \mathrm{C}$ was added lithium acetylide-EDA complex $(0.82 \mathrm{~g}, 8.87 \mathrm{mmol})$ in one portion. The reaction mixture was stirred at $0{ }^{\circ} \mathrm{C}$ for $30 \mathrm{~min}$ and over night at $\mathrm{rt}$. The excess of reagent was quenched with saturated ammonium chloride solution and extracted with EtOAc, washed with water, brine, dried $\left(\mathrm{Na}_{2} \mathrm{SO}_{4}\right)$, concentrated. The residue was purified by silica gel chromatography by eluting with light petroleum: EtOAc (7:3) to afford the alkyne product $(1.42 \mathrm{~g}, 86 \%)$ as a colorless liquid. $[\alpha]_{\mathrm{D}}+10.1\left(\right.$ c 1.05, $\left.\mathrm{CHCl}_{3}\right) ;{ }^{1} \mathrm{H} \mathrm{NMR}(200 \mathrm{MHz}): \delta$ 0.87 (t, $3 \mathrm{H}, J=6.4 \mathrm{~Hz}), 1.21-1.27$ (m, $8 \mathrm{H}), 1.47-1.65$ (m, $2 \mathrm{H}), 1.99$ (t, $1 \mathrm{H}, J=3.6 \mathrm{~Hz}), 2.05$ (s, OH), 2.43 (ddd, $2 \mathrm{H}, J=11.9,10.7,2.4 \mathrm{~Hz}), 3.42$ (s, $3 \mathrm{H}), 3.56$ (t, $2 \mathrm{H}, J=3.6 \mathrm{~Hz}), 3.62-3.86$ $(\mathrm{m}, 4 \mathrm{H}), 4.82(\mathrm{~d}, 2 \mathrm{H}, J=3.6 \mathrm{~Hz}), 4.92(\mathrm{~d}, 1 \mathrm{H}, J=6.9 \mathrm{~Hz}) ;{ }^{13} \mathrm{C}$ NMR $(50 \mathrm{MHz}): \delta 13.8,22.3$, 23.3, 24.9, 29.1, 30.5, 31.5, 58.6, 67.3, 70.0, 70.7, 71.5, 80.4, 80.6,95.4; Anal. Calcd for $\mathrm{C}_{15} \mathrm{H}_{28} \mathrm{O}_{4}$ : C, 66.14; H, 10.36. Found: C, 66.28; H, 10.21.

Above product $(1.0 \mathrm{~g}, 3.67 \mathrm{mmol})$, Lindlar catalyst $(20 \mathrm{mg})$ and quinoline $(5 \mathrm{mg})$ in benzene $(10 \mathrm{~mL})$ were stirred under hydrogen atmosphere at 1 bar for $30 \mathrm{~min}$. The catalyst was filtered, concentrated and the residue extracted with ethyl acetate, it was washed with $1 \mathrm{~N} \mathrm{HCl}$, water, dried $\left(\mathrm{Na}_{2} \mathrm{SO}_{4}\right)$ and purified by silica gel column chromatography eluting with light petroleum: EtOAc $(7: 3)$ to give $6(0.93 \mathrm{~g}, 91 \%)$ as a colorless oil. $[\alpha]_{\mathrm{D}}+38\left(c 0.9, \mathrm{CHCl}_{3}\right)$; ${ }^{1} \mathrm{H} \mathrm{NMR}$ 
(200MHz): $\delta 0.90(\mathrm{t}, 3 \mathrm{H}, J=6.6 \mathrm{~Hz}), 1.21-1.38(\mathrm{~m}, 8 \mathrm{H}), 1.44-1.61(\mathrm{~m}, 2 \mathrm{H}), 2.1-2.39(\mathrm{~m}, 2 \mathrm{H})$, $2.81(\mathrm{~s}, \mathrm{OH}), 3.37-3.49(\mathrm{~m}, 1 \mathrm{H}), 3.39$ (s, $3 \mathrm{H}), 3.52-3.84(\mathrm{~m}, 5 \mathrm{H}), 4.7-4.87$ (m, $2 \mathrm{H})$, 5.06-5.17 (m, $2 \mathrm{H}), 5.88$ (br ddt, $1 \mathrm{H}, J=17.4,10.6,7.0 \mathrm{~Hz}) ;{ }^{13} \mathrm{C} \mathrm{NMR}(50 \mathrm{MHz}): \delta 14.1,22.6,25.1,29.4$, $30.8,31.7,37.8,58.9,67.6,71.7,72.0,82.4$, 95.9, 117.1,134.9; Anal. Calcd for $\mathrm{C}_{15} \mathrm{H}_{30} \mathrm{O}_{4}$ : C, 65.66; H, 11.02. Found: C, 65.07; H, 10.83 .

(4R,5R)-4,5-Bis-benzyloxy-hept-6-enoic acid,(1'S,1'S)-1'-(1"'-[(2-methoxyethoxy)methoxy] 3'-butenyl ester (26). To a solution of compounds 5 (0.07 g, $0.25 \mathrm{mmol}), 6$ (0.08 g, $0.25 \mathrm{mmol})$ and DMAP (5 mg) in $\mathrm{CH}_{2} \mathrm{Cl}_{2}(2 \mathrm{~mL})$ was added DCC (0.057 $\left.\mathrm{g}, 0.27 \mathrm{mmol}\right)$. The reaction mixture was stirred at $\mathrm{rt}$ for $18 \mathrm{~h}$, filtered and evaporated to afford a residue, which on purification by silica gel column chromatography eluting with light petroleum: EtOAc (7:3) afforded $26(0.11 \mathrm{~g}, 76 \%)$ as a colorless liquid. $[\alpha]_{\mathrm{D}}+10.7\left(c 1.0, \mathrm{CHCl}_{3}\right) ;{ }^{1} \mathrm{H} \mathrm{NMR}(500 \mathrm{MHz})$ : $\delta 0.87(\mathrm{t}, 3 \mathrm{H}, J=6.9 \mathrm{~Hz}), 1.21-1.34(\mathrm{~m}, 8 \mathrm{H}), 1.46-1.54(\mathrm{~m}, 2 \mathrm{H}), 1.67-1.74(\mathrm{~m}, 1 \mathrm{H}), 1.88-1.95$ $(\mathrm{m}, 1 \mathrm{H}), 2.25-2.46(\mathrm{~m}, 4 \mathrm{H}), 3.37(\mathrm{~s}, 3 \mathrm{H}), 3.49-3.54(\mathrm{~m}, 3 \mathrm{H}), 3.58$ (br ddd, $1 \mathrm{H}, J=6.2,5.6$, $4.3 \mathrm{~Hz}), 3.66-3.73(\mathrm{~m}, 2 \mathrm{H}), 3.87$ (t, $1 \mathrm{H}, J=6.7 \mathrm{~Hz}), 4.38(\mathrm{~d}, 1 \mathrm{H}, J=11.9 \mathrm{~Hz}), 4.52(\mathrm{~d}, 1 \mathrm{H}, J=$ $11.4 \mathrm{~Hz}), 4.62(\mathrm{~d}, 1 \mathrm{H}, J=11.9 \mathrm{~Hz}), 4.71-4.77$ (m, $3 \mathrm{H}), 4.99-5.07$ (m, $3 \mathrm{H}), 5.27-5.33$ (m, $2 \mathrm{H})$, 5.71 (dddd, $1 \mathrm{H}, J=17.1,10.1,7.6,6.6 \mathrm{~Hz}$ ), 5.80 (ddd, $1 \mathrm{H}, J=17.3,10.6,7.6 \mathrm{~Hz}$ ), 7.25-7.30 $(\mathrm{m}, 10 \mathrm{H}) ;{ }^{13} \mathrm{C}$ NMR $(125 \mathrm{MHz}): \delta 14.1,22.6,25.4,26.3,29.4,30.5,31.8,34.7,59.0,67.5,70.6$, 71.8, 73.4, 78.1, 80.2, 82.60, 96.2, 117.6, 118.8, 127.5, 127.5, 127.7, 127.9, 128.33, 134.08, 135.2, 138.6, 138.7, 172.8; Anal. Calcd for $\mathrm{C}_{36} \mathrm{H}_{52} \mathrm{O}_{7}$ : C, 72.45; H, 8.78. Found: C, 72.08; H, 9.13 .

$(5 R, 6 R, 7 E, 10 S)-10-\left[\left(1^{\prime} S\right)-1 '-[(2-M e t h o x y e t h o x y) m e t h o x y]-5,6-b i s-b e n z y l o x y-3,4,5,6,9,10-\right.$ hexa hydro-2H-oxecin-2-one (27). A mixture of compound 26 (0.1 g, $0.16 \mathrm{mmol})$ and Grubbs' catalyst $(0.03 \mathrm{~g}, 0.0034 \mathrm{mmol})$ in degassed $\mathrm{CH}_{2} \mathrm{Cl}_{2}(100 \mathrm{~mL})$ was stirred under reflux for $28 \mathrm{~h}$. The reaction mixture evaporated and then purified on silica gel by eluting with light petroleum: EtOAc (7:3) to afford E-27 (0.063 g, $67 \%)$. [ $\alpha]_{\mathrm{D}}-41.1\left(\right.$ c $\left.0.52, \mathrm{CHCl}_{3}\right) ;{ }^{1} \mathrm{H} \mathrm{NMR} \mathrm{(500} \mathrm{MHz):} \delta$ 0.87 (t, $3 \mathrm{H}, J=6.9 \mathrm{~Hz}), 1.26-1.32(\mathrm{~m}, 8 \mathrm{H}), 1.54-1.59(\mathrm{~m}, 3 \mathrm{H}), 2.02$ (ddd, $1 \mathrm{H}, J=15.2,10.6$, $6.2 \mathrm{~Hz}$ ), 2.17 (ddd, $1 \mathrm{H}, J=14.7,10.6,1.4), 2.24-2.30$ (m, $2 \mathrm{H}), 2.61$ (dd, $1 \mathrm{H}, J=14.7,9.2 \mathrm{~Hz}$ ), 3.38 (s, 3 H), 3.54-3.56 (m, 2 H), 3.67-3.78 (m, 4 H), 4.07 (br. d, $1 \mathrm{H}, J=4.5$ Hz), 4.47 (d, 1 H, $J$ $=11.9 \mathrm{~Hz}), 4.48(\mathrm{~d}, 1 \mathrm{H}, J=12.5 \mathrm{~Hz}), 4.54(\mathrm{~d}, 1 \mathrm{H}, J=11.9 \mathrm{~Hz}), 4.65(\mathrm{~d}, 1 \mathrm{H}, J=12.5 \mathrm{~Hz})$, 4.78-4.81 (m, $2 \mathrm{H}), 5.15$ (dt, $1 \mathrm{H}, J=9.2,4.6 \mathrm{~Hz}), 5.64(\mathrm{dd}, 1 \mathrm{H}, J=15.8,2.1 \mathrm{~Hz}), 5.64-5.73(\mathrm{~m}$, $1 \mathrm{H}), 7.28-7.35$ (m, $10 \mathrm{H}) ;{ }^{13} \mathrm{C}$ NMR (125 MHz): $\delta$ 14.0, 22.6, 25.0, 29.4, 31.2, 31.7, 36.1, 59.0, 67.4, 71.3, 71.5, 71.8, 78.2, 95.4, 126.5, 127.2, 127.5, 127.6, 128.3, 128.4, 131.7, 138.5, 138.8, 175.17; Anal. Calcd for $\mathrm{C}_{34} \mathrm{H}_{48} \mathrm{O}^{-}{ }_{7}$ : C, 71.80; H, 8.51. Found: C, 71.97; H, 8.98.

Microcarpalide (1). To a solution of $27(0.053 \mathrm{~g}, 0.1 \mathrm{mmol})$ in anhydrous $\mathrm{CH}_{2} \mathrm{Cl}_{2}(2 \mathrm{~mL})$ under nitrogen at $0{ }^{\circ} \mathrm{C}$ was added $\mathrm{TiCl}_{4}(0.1 \mathrm{~mL}, 1 \mathrm{mmol})$. After $30 \mathrm{~min}$, excess of reagent was quenched with water, extracted with $\mathrm{CH}_{2} \mathrm{Cl}_{2}$, washed with water, dried $\left(\mathrm{Na}_{2} \mathrm{SO}_{4}\right)$, evaporated. The reaction mixture was purified on silica gel by eluting with light petroleum: EtOAc $(2: 3)$ to afford 1, which existed as a two slowly inter-converting conformers in a 76: 24 ratio $(0.022 \mathrm{~g}, 76 \%)$. $[\alpha]_{\mathrm{D}}-23.2$ (c 0.7, MeOH); Lit., ${ }^{2 \mathrm{a}}[\alpha]_{\mathrm{D}}-22$ (c 0.67, MeOH); ${ }^{1} \mathrm{H} \mathrm{NMR}\left(500 \mathrm{MHz}, \mathrm{CD}_{3} \mathrm{CN}\right)$ : (Major conformer) $\delta 0.92(\mathrm{t}, 3 \mathrm{H}, J=6.8 \mathrm{~Hz}), 1.28-1.38(\mathrm{~m}, 8 \mathrm{H}), 1.42-1.48(\mathrm{~m}, 2 \mathrm{H}), 1.72-1.83$ 
(m, $1 \mathrm{H}), 2.12-2.23(\mathrm{~m}, 4 \mathrm{H}), 2.28-2.37$ (m, $2 \mathrm{H}), 2.51$ (br m, $1 \mathrm{H}), 2.88$ (br s, OH), 3.12 (br s, $\mathrm{OH}$ ), 3.58 (br m, $1 \mathrm{H}$ ), 3.81 (br m, $1 \mathrm{H}$ ), 4.14 (br m, $1 \mathrm{H}$ ), 4.85 (ddd, $1 \mathrm{H}, J=7.9,4.7,3.4 \mathrm{~Hz}$ ), 5.53 (dddd, $1 \mathrm{H}, J=15.8,7.2,5.0,2.1 \mathrm{~Hz}), 5.73$ (dd, $1 \mathrm{H}, J=15.8,2.2 \mathrm{~Hz}) ;{ }^{13} \mathrm{C}$ NMR $(125$ $\left.\mathrm{MHz}, \mathrm{CD}_{3} \mathrm{CN}\right): \delta 14.4,23.3,26.1,26.4,29.9,32.5,34.2,36.7,72.3,72.8,73.5,79.7,126.6$, 134.5,176.3; Anal. Calcd for $\mathrm{C}_{16} \mathrm{H}_{28} \mathrm{O}^{-}{ }_{5}$ : C, 64.02; H, 9.40. Found: C, 64.17; H, 9.75.

3-Deoxy-5,6-dideoxy-1,2-O-isopropylidene- $\alpha$-D-ribohept-5-enofuranoside (30). Compound 29 (12.0 g, $48.75 \mathrm{mmol})$ was stirred with $0.8 \% \mathrm{H}_{2} \mathrm{SO}_{4}(10 \mathrm{~mL})$ in methanol $(300 \mathrm{~mL})$ at ambient temperature for $12 \mathrm{~h}$. After completion of the reaction (checked by TLC), the reaction mixture was neutralized with solid $\mathrm{NaHCO}_{3}$, filtered, concentrated and extracted with ethyl acetate. The combined organic layers were dried over $\mathrm{Na}_{2} \mathrm{SO}_{4}$ and concentrated. The residue was purified by silica gel column chromatography using acetone: ethyl acetate (1:4) to afford diol (8.42 g, 84\%) as white solid. MP.: $81-82{ }^{\circ} \mathrm{C}$; $[\alpha]_{\mathrm{D}}-14.0$ (c 1.2, EtOH); ${ }^{1} \mathrm{H}$ NMR $(200 \mathrm{MHz}): \delta 1.16(\mathrm{~s}, 3 \mathrm{H})$, $1.34(\mathrm{~s}, 3 \mathrm{H}), 1.68(\mathrm{t}, 1 \mathrm{H}, J=12.01 \mathrm{~Hz}), 1.92(\mathrm{~d}, 1 \mathrm{H}, J=12.02 \mathrm{~Hz}), 3.37(\mathrm{~m}, 1 \mathrm{H}), 3.51(\mathrm{~d}, 1$ $\mathrm{H}, J=11.25 \mathrm{~Hz}$ ), 3.68 (br s, $1 \mathrm{H}), 3.83$ (br s, $2 \mathrm{H}, 2-\mathrm{OH}), 4.01(\mathrm{~m}, 1 \mathrm{H}), 4.58(\mathrm{~s}, 1 \mathrm{H}), 5.84$ (s, 1 $\mathrm{H}) ;{ }^{13} \mathrm{C}$ NMR $(50 \mathrm{MHz}): \delta 26.1,26.7,33.8,63.5,72.4,78.4,80.5,105.2,116.2$; Anal: Calc for $\mathrm{C}_{9} \mathrm{H}_{16} \mathrm{O}_{5}$ : C, 53.43; $\mathrm{H}, 7.84$; found: $\mathrm{C}, 53.13$; $\mathrm{H}, 7.13$.

To a stirred solution of above diol $(7.10 \mathrm{~g}, 34.88 \mathrm{mmol})$ in $\mathrm{CH}_{2} \mathrm{Cl}_{2}(150 \mathrm{~mL})$, was added sodium meta periodate $(72.0 \mathrm{~g})$ adsorbed over silica gel $(200-400 \mathrm{mesh})$ at $0{ }^{\circ} \mathrm{C}$, and left at ambient temperature for $30 \mathrm{~min}$. After complete consumption of starting material (checked by TLC), the reaction mixture was filtered through sintered funnel, residue thoroughly washed with $\mathrm{CH}_{2} \mathrm{Cl}_{2}(2 \times 50 \mathrm{~mL})$. The combined organic layers were dried over $\mathrm{Na}_{2} \mathrm{SO}_{4}$ and concentrated to afford the crude aldehyde 30 (5.68 g, 95\%) as viscous liquid which was used as such for the next reaction.

3-Deoxy-5,6-dideoxy-1,2-O-isopropylidene- $\alpha$-D-ribohept furanoside (31). $n$-Butyl lithium (49 $\mathrm{mL}, 1.6 \mathrm{M}$ in hexane) was slowly added to a stirred solution of ethylene triphenylphosphonium bromide $(29.0 \mathrm{~g}, 78.2 \mathrm{mmol})$ in anhydrous THF $(200 \mathrm{~mL})$ at $-78{ }^{\circ} \mathrm{C}$ under nitrogen atmosphere. The stirring was continued at the same temperature for $1 \mathrm{~h}$. To the red wine colored solution, was added crude aldehyde $30(5.38 \mathrm{~g}, 31.27 \mathrm{mmol})$ in THF (50 $\mathrm{mL})$ drop wise at $-78{ }^{\circ} \mathrm{C}$. The stirring was continued for additional $3 \mathrm{~h}$ at $0{ }^{\circ} \mathrm{C}$. After complete consumption of starting material (checked by TLC), the reaction was quenched by slow addition of saturated ammonium chloride solution, extracted with ethyl acetate $(2 \times 100 \mathrm{~mL})$. The combined organic fractions were washed with brine, dried over $\mathrm{Na}_{2} \mathrm{SO}_{4}$, concentrated. The residue was purified by silica gel chromatography using ethyl acetate: light petroleum (1:9) to afford the Wittig product as a colorless liquid $(4.71 \mathrm{~g}, 82 \%)$. $[\alpha]_{\mathrm{D}}-23.4\left(\mathrm{c} 1.45, \mathrm{CHCl}_{3}\right) ;{ }^{1} \mathrm{H} \mathrm{NMR}(500 \mathrm{MHz}): \delta 1.31(\mathrm{~s}, 3$ H), $1.53(\mathrm{~s}, 3 \mathrm{H}), 1.55(\mathrm{dd}, 1 \mathrm{H}, J=13.2,4.2 \mathrm{~Hz}), 1.70(\mathrm{~d}, 3 \mathrm{H}, J=6.9 \mathrm{~Hz}), 2.11(\mathrm{dd}, 1 \mathrm{H}, J=$ 13.2, 4.2 Hz), 4.60 (t, $1 \mathrm{H}, J=4.3 \mathrm{~Hz}), 4.95(\mathrm{~m}, 1 \mathrm{H}), 5.36(\mathrm{t}, 1 \mathrm{H}, J=8.7 \mathrm{~Hz}), 5.63(\mathrm{~m}, 1 \mathrm{H})$, $5.69(\mathrm{~d}, 1 \mathrm{H}, J=3.9 \mathrm{~Hz}) ;{ }^{13} \mathrm{C} \mathrm{NMR}(125 \mathrm{MHz}): \delta 13.5,26.1,26.7,39.5,73.0,80.6,105.2,110.7$, 128.2, 129.0.; Anal. Calcd for $\mathrm{C}_{10} \mathrm{H}_{16} \mathrm{O}_{3}$ : C, 65.19; H, 8.75 Found: C, 64.76; H, 8.92.

Palladium charcoal $(100 \mathrm{mg}$ ) was added to the above product (4.60 g, $27.17 \mathrm{mmol})$ in ethyl acetate $(40 \mathrm{~mL})$. It was stirred under $\mathrm{H}_{2}$ atmosphere (1 atmosphere) at $\mathrm{rt}$ for $3 \mathrm{~h}$. The reaction 
mixture was filtered, thoroughly washed the solid residue with ethyl acetate, concentrated to afford crude product which was purified by silica gel column chromatography using ethyl acetate: light petroleum (1:9) to give 31 as a colorless liquid $(4.27 \mathrm{~g}, 92 \%)$. $[\alpha]_{\mathrm{D}}-12.5(c 0.80$, $\left.\mathrm{CHCl}_{3}\right) ;{ }^{1} \mathrm{H}$ NMR $(500 \mathrm{MHz}): \delta 0.94(\mathrm{t}, 3 \mathrm{H}, J=7.58 \mathrm{~Hz}), 1.26(\mathrm{~m}, 2 \mathrm{H}), 1.29(\mathrm{~s}, 3 \mathrm{H}), 1.41(\mathrm{~m}$, $2 \mathrm{H}), 1.49(\mathrm{~s}, 3 \mathrm{H}), 1.61(\mathrm{~m}, 1 \mathrm{H}), 2.05(\mathrm{~m}, 1 \mathrm{H}), 4.15(\mathrm{~m}, 1 \mathrm{H}), 4.68(\mathrm{~s}, 1 \mathrm{H}), 5.76(\mathrm{~s}, 1 \mathrm{H}) ;{ }^{13} \mathrm{C}$ NMR (125 MHz): $\delta 14.1,19.2,26.0,26.5,36.3,39.0,77.5,80.4,105.1,110.5 ; \mathrm{MS}(\mathrm{EI}): \mathrm{m} / \mathrm{z}$ $187[\mathrm{M}+\mathrm{H}]^{+}$; Anal. Calcd for $\mathrm{C}_{10} \mathrm{H}_{18} \mathrm{O}_{3}:$ C, 64.48; H, 9.74. Found: C, 63.98; H, 9.16.

Oct-1-ene-(3R, 5R)-diol (32). Compound $31(4.30 \mathrm{~g}, 23.11 \mathrm{mmol})$ in $20 \%$ aqueous acetic acid ( $40 \mathrm{~mL}$ ) and few drops of concentrated $\mathrm{H}_{2} \mathrm{SO}_{4}$ was refluxed for about $6 \mathrm{~h}$. Then reaction mixture was brought to rt, neutralized by addition of solid sodium carbonate. It was partitioned between ethyl acetate and water, the organic layer was washed with brine, dried over $\mathrm{Na}_{2} \mathrm{SO}_{4}$, concentrated to obtain the crude product which was passed through a short bed of silica gel using ethyl acetate: light petroleum (1:1) to afford the pure lactol $32(3.14 \mathrm{~g}, 93 \%)$. This unstable product was used immediately in next step without characterization.

(3R)-(4-Methoxybenzyloxy)-oct-1-ene-(5R)-ol (11). To the solution of methylene triphenyl phosphonium iodide $(26.0 \mathrm{~g}, 64.5 \mathrm{mmol})$ in anhydrous THF $(175 \mathrm{~mL})$, was added $n$-butyl lithium $\left(40 \mathrm{~mL}, 1.6 \mathrm{M}\right.$ in hexane) drop wise at $0{ }^{\circ} \mathrm{C}$ under $\mathrm{N}_{2}$ atmosphere. After $1 \mathrm{~h}$, lactol 32 $(3.14 \mathrm{~g}, 21.50 \mathrm{mmol})$ in THF $(30 \mathrm{~mL})$ was slowly added while maintaining the reaction temperature $0{ }^{\circ} \mathrm{C}$. The reaction mixture was brought to rt slowly and allowed to stir for additional $11 \mathrm{~h}$. The reaction mixture was quenched with saturated ammonium chloride solution, extracted with ethyl acetate $(3 \times 100 \mathrm{~mL})$ and the combined organic layers were washed with brine, dried $\left(\mathrm{Na}_{2} \mathrm{SO}_{4}\right)$, concentrated to get the crude product which was purified by silica gel column chromatography using ethyl acetate: light petroleum (1:3) to afford diol as a colorless liquid $(2.35 \mathrm{~g}, 76 \%) .[\alpha]_{\mathrm{D}}+32\left(c, 0.8, \mathrm{CHCl}_{3}\right) ;{ }^{1} \mathrm{H}$ NMR $(500 \mathrm{MHz}): \delta 0.91(\mathrm{t}, 3 \mathrm{H}, J=0.91 \mathrm{~Hz})$, 1.32-1.47 (m, $4 \mathrm{H}), 1.52-1.59$ (m, $2 \mathrm{H}), 3.85$ (br s, $1 \mathrm{H}$ ), 4.32 (br s, $1 \mathrm{H}), 5.05$ (d, $1 \mathrm{H}, J=10.81$, Hz) $5.21(\mathrm{~d}, 1 \mathrm{H}, J=10.81 \mathrm{~Hz}), 5.83(\mathrm{ddd}, 1 \mathrm{H}, J=16.29,10.39,5.90 \mathrm{~Hz}) ;{ }^{13} \mathrm{C}$ NMR $(125$ MHz): $\delta$ 13.8, 18.3, 39.8, 42.5, 73.0, 114.0, 140.5; Anal. Calcd. for $\mathrm{C}_{8} \mathrm{H}_{16} \mathrm{O}_{2}: \mathrm{C}, 66.63 \mathrm{H}, 11.18$ Found: C, $66.21 \mathrm{H}, 10.45$.

To a solution of diol $(1.0 \mathrm{~g}, 6.94 \mathrm{mmol})$ in dry dimethyl formamide (DMF) $(8 \mathrm{~mL})$, was added sodium hydride ( $199 \mathrm{mg}, 8.33 \mathrm{mmol}$ ) at $0{ }^{\circ} \mathrm{C}$ under $\mathrm{N}_{2}$ atmosphere and allowed to stir at $\mathrm{rt}$ for 45 min. $p$-Methoxy benzyl chloride (PMB-Cl) $(1.30 \mathrm{~g}, 8.32 \mathrm{mmol})$ in DMF (2 mL) was added drop wise. After stirring $1 \mathrm{~h}$ under this condition, the reaction mixture was quenched with cold water, extracted with ether $(2 \times 50 \mathrm{~mL})$, dried $\left(\mathrm{Na}_{2} \mathrm{SO}_{4}\right)$, and concentrated to afford the crude product. Purification by silica gel column chromatography using ethyl acetate: petroleum ether (3:7) gave pure product 11 as colorless liquid $(1.72 \mathrm{~g}, 94 \%)$. [ $\alpha]_{\mathrm{D}}-5.8\left(\right.$ c $\left.0.55, \mathrm{CHCl}_{3}\right) ;{ }^{1} \mathrm{H} \mathrm{NMR}$ (200 MHz): $\delta 0.94$ (t, $3 \mathrm{H}, J=6.9 \mathrm{~Hz}), 1.40-1.25(\mathrm{~m}, 4 \mathrm{H}), 1.75-1.62(\mathrm{~m}, 2 \mathrm{H}) 3.56$ (br s, $1 \mathrm{H})$, 3.79 (s, $4 \mathrm{H}), 4.01(\mathrm{~m}, 1 \mathrm{H}), 4.28(\mathrm{~d}, 1 \mathrm{H}, J=11.1 \mathrm{~Hz}), 4.56(\mathrm{~d}, 1 \mathrm{H}, J=11.1 \mathrm{~Hz}), 5.32-5.16(\mathrm{~m}$, $2 \mathrm{H}), 5.74(\mathrm{~m}, 1 \mathrm{H}), 6.85(\mathrm{~d}, 2 \mathrm{H}, J=8.3 \mathrm{~Hz}), 7.22(\mathrm{~d}, 2 \mathrm{H}, J=8.3 \mathrm{~Hz}) ;{ }^{13} \mathrm{C}$ NMR $(50 \mathrm{MHz}): \delta$ 14.1, 18.6, 39.8, 42.5, 55.2, 69.8, 71.1, 81.2, 113.9, 117.5, 124.5, 129.9, 138.3, 159.3; Anal. Calcd for $\mathrm{C}_{16} \mathrm{H}_{24} \mathrm{O}_{3}$ : C, 72.69; H, 9.15. Found: $\mathrm{C}, 73.24 ; \mathrm{H}, 9.08$ 
(3R)-Hydroxy-1-propyl-pent-4-enyl hex-(5R)-enoate (10). To a solution of 5-hexenoic acid 12 (500 mg, $4.38 \mathrm{mmol})$ in THF, was added triethyl amine $(1.0 \mathrm{~mL}, 6.57 \mathrm{mmol})$ and 2, 4, 6trichloro benzoyl chloride $(1.0 \mathrm{~mL}, 6.57 \mathrm{mmol})$ under nitrogen atmosphere at $0{ }^{\circ} \mathrm{C}$ and the reaction mixture was allowed to stir under this condition for $1 \mathrm{~h}$. To this, alcohol 11 (925 mg, $3.50 \mathrm{mmol})$ in THF $(5 \mathrm{~mL})$ and catalytic amount of 4-dimethyl aminopyridine (DMAP) were added successively at $0{ }^{\circ} \mathrm{C}$. Stirring was continued for additional $3 \mathrm{~h}$ at $\mathrm{rt}$. The reaction mixture was quenched with water and extracted with ethyl acetate $(3 \times 50 \mathrm{~mL})$. The combined organic layers were thoroughly washed with saturated sodium bicarbonate solution, brine, dried $\left(\mathrm{Na}_{2} \mathrm{SO}_{4}\right)$, and concentrated to afford the crude product which was purified by silica gel column chromatography using ethyl acetate: light petroleum $(1: 19)$ to afford the ester as a colorless liquid $(1.03 \mathrm{~g}, 82 \%)$. $[\alpha]_{\mathrm{D}}+31.1\left(\mathrm{c} 0.60, \mathrm{CHCl}_{3}\right) ;{ }^{1} \mathrm{H} \mathrm{NMR}(200 \mathrm{MHz}): \delta 0.86(\mathrm{t}, 3 \mathrm{H}, J=6.6$ $\mathrm{Hz}), 1.26(\mathrm{~m}, 2 \mathrm{H}), 1.43(\mathrm{~m}, 2 \mathrm{H}), 1.65(\mathrm{~m}, 3 \mathrm{H}), 2.03(\mathrm{~m}, 3 \mathrm{H}), 2.20(\mathrm{t}, 2 \mathrm{H}, J=7.1 \mathrm{~Hz}), 3.73$ $(\mathrm{m}, 1 \mathrm{H}), 3.78(\mathrm{~s}, 3 \mathrm{H}), 4.23(\mathrm{~d}, 1 \mathrm{H}, J=11.4 \mathrm{~Hz}), 4.50(\mathrm{~d}, 1 \mathrm{H}, J=11.4 \mathrm{~Hz}), 5.28-4.95(\mathrm{~m}, 5 \mathrm{H})$, 5.85-5.61 (m, $2 \mathrm{H}), 6.84(\mathrm{~d}, 2 \mathrm{H}, J=8.3 \mathrm{~Hz}), 7.21(\mathrm{~d}, 2 \mathrm{H}, J=8.3 \mathrm{~Hz})$; NMR (50 MHz, $\left.\mathrm{CDCl}_{3}\right)$ : $\delta 13.9,18.4,24.1,33.1,33.7,36.6,40.0,55.1,69.5,71.0,77.3,113.6,115.3,118.0,129.3,130.5$, 137.7, 138.3, 159.0, 172.8; Anal. Calcd for $\mathrm{C}_{22} \mathrm{H}_{32} \mathrm{O}_{4}$ : C, 73.30; H, 8.95 Found: C, 73.68; H, 9.24.

To a solution of above ester $(500 \mathrm{mg}, 1.38 \mathrm{mmol})$ in acetronitile $(10 \mathrm{~mL})$ and water $(0.5 \mathrm{~mL})$ was added 2,3-Dichloro-5,6-dicyano benzoquinone (DDQ) (407 mg, $1.79 \mathrm{mmol}$ ). Reaction mixture was stirred at $\mathrm{rt}$ for $30 \mathrm{~min}$. After completion (monitored by TLC), the reaction mixture was extracted with ethyl acetate $(3 \times 40 \mathrm{~mL})$. The combined organic fractions were washed with saturated sodium bicarbonate solution followed by brine, dried $\left(\mathrm{Na}_{2} \mathrm{SO}_{4}\right)$, concentrated to afford the crude product which was on purification by silica gel column chromatography using acetate: light petroleum (1:19) afforded compound $\mathbf{1 0}$ as a oily liquid $(313 \mathrm{mg}, 94 \%)$. $[\alpha]_{\mathrm{D}}+3.6(c 1.1$, $\left.\mathrm{CHCl}_{3}\right) ;{ }^{1} \mathrm{H}$ NMR $(200 \mathrm{MHz}): \delta 0.87(\mathrm{t}, 3 \mathrm{H}, J=7.1 \mathrm{~Hz}), 1.39-1.22(\mathrm{~m}, 2 \mathrm{H}), 1.90-1.48(\mathrm{~m}, 6 \mathrm{H})$, 2.05 (q, $2 \mathrm{H}, J=14.1,6.9 \mathrm{~Hz}), 2.25$ (t, $2 \mathrm{H}, J=7.2 \mathrm{~Hz}$ ), 2.48 (br s, $1 \mathrm{H}$ ), 4.11 (q, $1 \mathrm{H}, J=12.5$, $6.4 \mathrm{~Hz}), 5.22-4.87(\mathrm{~m}, 5 \mathrm{H}), 5.89-5.63(\mathrm{~m}, 2 \mathrm{H}) ;{ }^{13} \mathrm{C} \mathrm{NMR}(50 \mathrm{MHz}): \delta 13.8,18.3,24.0,33.0$, 33.7, 36.6, 41.5, 70.3, 71.4, 114.7, 115.3, 137.5, 140.5, 173.3; Anal. Calcd for $\mathrm{C}_{14} \mathrm{H}_{24} \mathrm{O}_{3}$ : C, 69.96; H, 10.06. Found: C, 69.52; H, 9.67.

\section{Herbarumin III (4)}

Ring closing metathesis of diene 10 with first generation Grubbs' catalyst. A mixture of 10 (100 $\mathrm{mg}, 0.40 \mathrm{mmol})$ in anhydrous $\mathrm{CH}_{2} \mathrm{Cl}_{2}(100 \mathrm{~mL})$ and Grubbs' first generation catalyst (45 $\mathrm{mg}, 0.05 \mathrm{mmol}$ ) was degassed with argon for $15 \mathrm{~min}$ and refluxed for 4 days by the time TLC showed the consumption of only half of the starting diene. At this stage, the reaction was stopped and allowed to bring to room temperature. Solvent was removed under reduced pressure to leave highly dark brown colored residue. The crude product was purified by column chromatography using ethyl acetate: light petroleum (1:9) to afford herbarumin III (4) as colorless liquid (31 mg, $36 \%)$. 
Ring closing metathesis of diene 10 with second generation Grubbs' catalyst. A mixture of 10 (100 mg, $0.40 \mathrm{mmol})$ in anhydrous $\mathrm{CH}_{2} \mathrm{Cl}_{2}(100 \mathrm{~mL})$ and Grubbs' second generation catalyst (15 mg, $0.003 \mathrm{mmol}$ ) was degassed with argon for $15 \mathrm{~min}$, and refluxed for $16 \mathrm{~h}$. Solvent was removed under reduced pressure to leave highly dark brown colored residue. The crude product was purified by ethyl acetate: light petroleum (1:9) to afford analytically pure herbarumin III (4) as a colorless liquid (68 mg, $76 \%$ ). $[\alpha]_{\mathrm{D}}+20.6$ (c 1.2, EtOH); IR $\left(\mathrm{CHCl}_{3}\right)$ : 3443, 3019, 2962, 1723, $1640 \mathrm{~cm}^{-1} ;{ }^{1} \mathrm{H}$ NMR (500 MHz): $\delta 0.91(\mathrm{t}, 3 \mathrm{H}, J=7.4 \mathrm{~Hz}), 1.33(\mathrm{~m}, 2 \mathrm{H}), 1.42(\mathrm{~m}, 1 \mathrm{H})$, 1.54 (dddd, $1 \mathrm{H}, J=13.8,9.3,8.6,4.9 \mathrm{~Hz}), 1.77(\mathrm{~m}, 1 \mathrm{H}), 1.82(\mathrm{~m}, 1 \mathrm{H}), 1.84(\mathrm{~m}, 1 \mathrm{H}), 1.98(\mathrm{~m}$, $1 \mathrm{H}), 1.99(\mathrm{~m}, 1 \mathrm{H}), 2.00(\mathrm{~m}, 1 \mathrm{H}), 2.28(\mathrm{dd}, 1 \mathrm{H}, J=6.1,13.0 \mathrm{~Hz}), 2.37(\mathrm{~m}, 1 \mathrm{H}), 4.42(\mathrm{t}, 1 \mathrm{H}, J$ $=2.4 \mathrm{~Hz}), 5.30(\mathrm{~m}, 1 \mathrm{H}) 5.46(\mathrm{~m}, 1 \mathrm{H}), \delta 5.62(\mathrm{~d}, 1 \mathrm{H}, J=16.1 \mathrm{~Hz}) ;{ }^{13} \mathrm{C} \mathrm{NMR}(125 \mathrm{MHz})$ : $\delta 13.9,18.426 .0,33.7,34.6,37.4,40.6,67.8,68.0,124.9,134.6,176.7$; Anal. Calcd for $\mathrm{C}_{12} \mathrm{H}_{20} \mathrm{O}_{3}$ : C, 67.89; H, 9.50. Found: C, 67.42; H, 9.84

\section{Acknowledgements}

NP and GSY thank CSIR, New Delhi for award of Research Fellowships.

\section{References}

1. Brown, H. C.; Fletcher, R. S.; Johansen, R. B. J. Am. Chem. Soc. 1951, 73, 214. (b) Eliel, E. in Stereochemistry of Carbon Compounds McGraw-Hill: New York, 1962; p 189.

2. Ratnayake, A. S.; Yoshida, W. Y.; Moobery, S. L.; Hemscheidt, T. Org. Lett. 2001, 3, 3479. (b) Cooper, J. A. J. Cell Biol. 1987, 105, 1473.

3. Bodo, B.; Molho, L.; Davoust, D.; Molho, D. Phytochemistry 1983, 22, 447. (b) Evidente, A.; Lanzetta, R.; Capasso, R.; Vurro, M.; Bottalico, A. Phytochemistry 1993, 34, 999. (c) Evidente, A.; Capasso, R.; Abouzeid, M.A.; Lanzetta, R.; Vurro, M.; Bottalico, A. J. Nat. Prod. 1993, 56, 1937. (d) Rivero-Cruz, J. F.; Garcia-Aguirre, G.; Cerda-Gracias-Rojas.; Mata, R. Tetrahedron 2000, 56, 5337. (e) Rivero-Cruz, J. F.; Macias, M.; Garcia-Aguirre, G.; Cerda-Gracias-Rojas.; Mata, R. J. Nat. Pro. 2003, 66, 511.

4. Murga, J.; Falomir, E.; Garcia-Fortanet, J.; Carda, M.; Marco, J. A. Org. Lett. 2002, 4, 3447. (b) Gurjar, M. K.; Nagaprasad, R.; Ramana, C. V. Tetrahedron Lett. 2003, 44, 2873. (c) Davoli, P.; Spaggiai, A.; Castagnetti, L.; Prati, F. Org. Biomol. Chem. 2004, 2, 38. (d) Banwell, G. M.; Loong, J. T. D. Heterocycles 2004, 62, 713. (e) Ishigami, K.; Kitahara, T. Heterocycles 2003, 63, 765.

5. Reviews: (a) Trnka, T. M.; Grubbs, R. H. Acc. Chem. Res. 2001, 34, 18. (b) Fürstner, A. Angew. Chem. 2000, 112, 3140; Angew. Chem., Int. Ed. 2000, 39, 3012. (c) Grubbs, R. H.; Chang, S. Tetrahedron 1998, 54, 4413. (d) Fürstner, A. Top. Catal. 1997, 4, 285. (e) Schuster, M.; Blechert, S. Angew. Chem. 1997, 109, 2124; Angew. Chem., Int. Ed. 1997, 36, 
2037. (f) Schrock, R. R. Top Organomet. Chem. 1998, 1, 1. (g) Maier, M. E. Angew. Chem. 2000, 112, 2153; Angew. Chem., Int. Ed. 2000, 39, 2073. For syntheses of 10-membered rings by RCM, see: (h) Fürstner, A.; Müller, T. Synlett 1997, 1010. (i) Chang, S.; Grubbs, R. H. Tetrahedron Lett. 1997, 38, 4757. (j) Gerlach, K.; Quitschalle, M.; Kalesse, M. Synlett 1998, 1108. (k) Fink, B. E.; Kym, P. R.; Katzenellenbogen, J. A. J. Am. Chem. Soc. 1998, 120, 4334. (1) Oishi, T.; Nagumo, Y.; Hirama, M. Chem. Commun. 1998, 1041. (m) Quitschalle, M.; Kalesse, M. Tetrahedron Lett. 1999, 40, 7765. (n) Delgado, M.; Martin, J. D. J. Org. Chem. 1999, 64, 4798. (o) Bamford, S. J.; Goubitz, K.; Van Lingen, H. L.; Luker, T.; Schenk, H.; Hiemstra, H. J. Chem. Soc., Perkin Trans. 1 2000, 345. (p) Nakashima, K.; Ito, R.; Sono, M.; Tori, M. Heterocycles 2000, 53, 301. (q) Cho, S. C.; Dussault, P. H.; Lisec, A. D.; Jensen, E. C.; Nickerson, K. W. J. Chem. Soc., Perkin Trans. 1 1999, 193. (r) Nevalainen, M.; Koskinen, A. M. P. Angew. Chem. 2001, 113, 4184; Angew. Chem., Int. Ed. 2001, 40, 4060. (s) Heinrich, M. R.; Steglich, W. Tetrahedron Lett. 2001, 42, 3287. (t) Banwell, M. G.; Bray, A. M.; Edwards, A. J.; Wong, D. J. New J. Chem. 2001, 25, 1347. (u) Telser, J.; Beumer, R.; Bell, A. A.; Ceccarelli, S. M.; Montio, D.; Gennari, C. Tetrahedron Lett. 2001, 42, 9187.

6. Keck, E. G.; Boden, P. E. J. Org. Chem. 1985, 50, 2394.

7. Rama Rao, A. V.; Reddy, E. R.; Joshi, B. V.; Yadav, J. S. Tetrahedron Lett. 1987, $28,6497$.

8. (a) Sharpless, K. B.; Amberg, W.; Bennani, Y. L.; Crispino, G. A.; Hartung, J.; Jeong, K.-S.; Kwong, H.-L.; Morikawa, K.; Wang, Z.-M.; Xu, D.; Zhang, X.-L. J. Org. Chem. 1992, 57, 2768. (b) Kolb, H. C.; Van-Nieuwenhze, M. S.; Sharpless, K. B. Chem. Rev. 1994, 94, 2483.

9. Rivero-Cruz, J. S.; Macias, M.; Cerda-Garcia, C. M.; Mata, R. J. Nat. Prod. 2003, 66, 511.

10. Gurjar, M. K.; Karmakar, S.; Mohapatra, D. K. Tetrahedron Lett. 2004, 45, 4525.

11. (a) Moore, B. S.; Cho, H.; Casati, R.; Kennedy, E.; Reynolds, K. A.; Mocek, U.; Beale, J. M.; Floss, H. G. J. Am. Chem. Soc. 1993, 115, 5254. (b) Coutrot, P.; Grison, C.; Lecouvey, M. Bull. Soc. Chim. Fr. 1997, 134, 27.

12. Criegee, R. Ber. 1931, 64, 260.

13. Corey, E. J.; Gras, J. -L.; Ulrich, P. Tetrahedron. Lett. 1976, 809.

14. Robins, M. J.; Hawrelak, S. D.; Kanai, T.; Siefert, J. -M.; Mengel. R. J. Org. Chem. 1979, 44, 1317.

15. Corey, E. J.; Venkateswarulu, A. J. Am. Chem. Soc. 1972, 94, 6190.

16. Nicaolou, K. C.; Webber, S. E. Synthesis 1986, 453.

17. (a) Corey, E. J.; Pyne, S.G. Tetrahedron Lett. 1983, 24, 4833. (b) Smith, A. B., III; Qiu, Y.; Jones, D. R.; Kobayashi, K. J. Am. Chem. Soc. 1995, 117, 12011.

18. Monti, H.; Leandri, G.; Klos-Ringuet, M.; Corriol, C. Synth. Commun. 1983, 13, 1021.

19. (a) Mancuo, A. J.; Swern, D. Synthesis 1981, 165. (b) Dalcanale, E.; Montanari, F. J. Org. Chem. 1986, 51, 567.

20. Liav, A.; Goren, M. B. Carbohydr. Res. 1984, 131, C8.

21. (a) Angyal, S. J.; Beveridge, R. J. Carbohydr. Res. 1978, 65, 279. (b) Liu, G.; Wang, Z. Synthesis 2001, 119. 
22. Hanack, M.; Kunzmann, E.; Schumacher, W. Synthesis 1978, 26.

23. Lindlar, H.; Dubuis, R. Organic Syntheses, Wiley: New York 1973, Collect. Vol. V, p 880.

24. Bhatt, M. V.; Kulkarni, S. V. Synthesis 1983, 249.

25. (a) Schmidt, O. T. In Methods in Carbohydrate Chemistry; Whistler, R. L.; Wolfrom, M. L., Ed.; Academic Press Inc.: New York, 1963; Vol. 2, p318. (b) Barton, D. H. R.; McCombie, S. W. J. Chem. Soc., Perkin Trans. 1 1975, 1574.

26. Zhong, Y. L.; Shing, T. K. M. J. Org. Chem. 1997, 62, 2622.

27. Freeman, F.; Robarge, K. D. Carbohydr. Res. 1986, 154, 270.

28. Krapcho, A. P. Synthesis 1982, 805 and 893.

29. Jnanaga, J.; Hirata, K.; Saeki, H.; Katsuki, T.; Yamaguchi, M. Bull. Chem. Soc. Jpn. 1979, 52, 1989. 